\title{
ESTUDIOS
}

\section{Miryam Singer González: Premio Nacional de Artes Musicales 2020. Perfil de su trayectoria en Chile}

\author{
Miryam Singer González: National Prize for Musical Arts \\ 2020. Profile of her career in Chile
}

\author{
por \\ Carmen Peña Fuenzalida \\ Instituto de Música, Pontificia Universidad Católica de Chile, Chile \\ cpenaf@uc.cl
}

\begin{abstract}
Este texto presenta un perfil de la actividad musical desarrollada en Chile por Miryam Singer González, merecedora del Premio Nacional de Artes Musicales 2020. Se circunscribe a su labor como cantante, directora y régie de ópera y a su activa participación en proyectos institucionales y privados de producción y difusión musical, dirigidos a diversos públicos, materializados en temporadas de conciertos y de ópera, giras, festivales, documentales, entre otros, gracias a una eficaz gestión cultural. En la medida de lo posible, se ha querido dejar testimonio tanto de la opinión de críticos acerca de su desempeño artístico como de su propio pensamiento. Las principales fuentes que nutren este trabajo son críticas de prensa, la mayoría reunida por la propia Miryam Singer y alojadas en su sitio web, algunas bases de datos informativas, registros audiovisuales de sus producciones y entrevistas a distintos medios.

Palabras clave: Miryam Singer González, ópera en Chile, cantantes chilenas, régisseur de ópera, régie, Premio Nacional de Artes Musicales.
\end{abstract}

This text presents a profile of the musical activity developed in Chile by Miryam Singer González, winner of the 2020 National Prize for Musical Arts. It is limited to her work as a singer, director, and opera régisseur, and to her active participation in institutional and private production projects of musical diffusion, aimed at different audiences, materialized in concert and opera seasons, festivals, documentaries, among others, thanks to an effective cultural management. As far as possible, I present testimonies both from the opinion of critics about his artistic performance, as well as from her own thinking. The main sources that feed this work are press reviews, most of them gathered by Miryam Singer herself and hosted on her website, some informative databases, audiovisual records of her productions and interviews with different media.

Keywords: Miryam Singer González, opera in Chile, Chilean singers, stage director, régie, National Prize for Musical Arts.

\section{INTRODUCCIÓN}

Miryam Singer González es la cuarta mujer en recibir el Premio Nacional de Artes Musicales en 2020. Inauguró el ingreso de las mujeres a este galardón Margot Loyola Palacios (1994), a la que siguieron Elvira Savi Federici (1998) y Carmen Luisa Letelier Valdés (2010), todas maestras con las que Singer se vinculó personal y artísticamente (De la Sotta y Gómez 2020). 
Multifacética en su formación y con una amplia visión de mundo, Miryam Singer es como un torbellino permanente de ideas y proyectos que quiere realizar-todos-operativa y rápidamente. De conversación tranquila y fluida, no exenta de humor y, a veces, algo de ironía, con frecuencia puede ser poética y emotiva, especialmente cuando de música y ópera se trata.

Es Profesora Titular del Instituto de Música de la Pontificia Universidad Católica de Chile, a cargo del Taller de Ópera, Directora de Artes y Cultura de la Vicerrectoría de Investigación de la misma Universidad desde 2010 y, a mi juicio, una activista del arte operático en nuestro país desde sus inicios hasta la actualidad.

Hija de padre alemán y madre chilena, nació en el norte de Chile, en la oficina salitrera Victoria en 1954, y desde pequeña estuvo en contacto con el arte y la música, pero no precisamente con el canto. Su padre era de gustos sinfónicos y su mamá tocaba el piano. Sin embargo, desde niña ella cantaba mucho. A los diecisiete años se trasladó a Santiago a estudiar primero arquitectura y luego canto, ambas carreras en la Universidad de Chile.

En 1974 se casó con el ingeniero Miguel Nussbaum y se fue a Israel donde permaneció cuatro años, primero viviendo en un kibbutz y luego en Tel Aviv. Allí quiso ingresar a estudiar canto en la Universidad de Tel Aviv, sin embargo, no pudo hacerlo al no conocer el repertorio para rendir el examen de admisión. Pese al intento de ponerse al día, finalmente decidió estudiar Filosofía e Historia del Arte. Por tanto, al llegar a Chile, se reintegró a sus estudios de arquitectura y en 1980 recién inició su formación en el conservatorio, para ello preparó "Oh del mio dolce" de la ópera Paride ed Elena de Christoph W. Gluck. Cuando ingresó como alumna de Clara Oyuela tenía veinticuatro años.

En 1982 se recibió de arquitecta en la Universidad de Chile. Al año siguiente, junto con su esposo y familia se trasladó a Atlanta y continuó sus estudios de canto bajo la tutela de Betty Boone, profesora, en esos años, en George State University. De regreso a Chile volvió a sus clases con Clara Oyuela, esta vez en el Teatro Municipal. Fue entonces cuando audicionó con Juan Pablo Izquierdo para cantar el Réquiem de Wolfgang Amadeus Mozart. Este fue el primer paso que, prontamente, la condujo a una trayectoria artística como cantante, lo que también implicó un estilo de vida disciplinado, sano y riguroso, siempre cuidándose para que sus cuerdas no se resintieran, toda vez que, como dice, "uno tiene el instrumento puesto" (Matamoros 2020).

Posteriormente, entre 1985 y 1988, estuvo en Europa con su familia y estudió con las maestras Aila Ernst en Zurich y en 1989 con Sara Corti en Milán, a quienes recuerda con especial cariño. Señala que con la primera aprendió lo que era "hacer música", la musicalidad, y con la segunda, con quien realizó un intenso trabajo, que la educó para ser cantante de ópera. Ella "me fabricó el instrumento", declara (Peña 2021).

Entre viajes al extranjero, estudios y vueltas a Chile, Singer cantó diverso repertorio, como se verá más adelante. Pero no solo el canto la apasionaba. Su formación de arquitecta también incidió en el inicio de su carrera como régisseur, la que hasta ahora comparte con la docencia y la gestión cultural.

\section{MIRYAM SINGER: LA CANTANTE}

Entre sus inicios en 1984 y hasta 2009, año en que se despidió del canto, Singer interpretó variado repertorio como solista de ópera y de música sinfónico-coral, bajo la dirección de connotados directores y en distintos escenarios. Hizo su primera régie en 1995 y, finalmente, se dedicó por completo a la producción y dirección de ópera, aspecto que se abordará en el siguiente acápite. La revisión de una selección de críticas de sus actuaciones permite corroborar lo antes dicho, al mismo tiempo que ilumina respecto de algunos estímulos que 
la condujeron a tomar el camino hacia la dirección. No obstante, es importante señalar que el período activo de Singer como cantante, desafortunadamente, coincide con la etapa de declinación de la crítica musical en los medios de comunicación escrita del país, pese a que ciertos espacios se mantuvieron gracias a unos pocos críticos que pudieron permanecer en el oficio (Peña 2019; Spencer 2004). Por tal razón, los registros son escasos, dispersos y los nombres se reiteran. A esto se suma la imposibilidad de revisar actualmente material impreso en bibliotecas debido a la pandemia de Covid-19. Sin embargo, la propia Miryam Singer conservó críticas y programas de mano a disposición pública en su sitio web, así como también hay acceso libre a ciertas bases de datos que, al menos, informan acerca de algunas de sus interpretaciones y producciones de ópera.

A pocos meses de audicionar con Juan Pablo Izquierdo, en abril de 1985 interpretó el Réquiem de Mozart, en el cuarto programa de abono del Teatro Municipal, junto con la Orquesta Filarmónica dirigida por dicho conductor. Federico Heinlein destacó su participación en una de las partes de la obra, señalando:

El cuarteto de solistas unió la calidez de la contralto Aída Reyes y la experiencia del bajo Mariano de la Maza con el frescor expresivo de la soprano Miryam Singer y el claro metal del tenor Ronnie Burger. Fue una interesante mezcla de elementos fogueados con figuras nuevas, más que promisorias (Heinlein 1985a).

Poco más tarde -septiembre-, el comentario de Víctor Muñoz registró su actuación en 1985 en la ópera Andrea Chenier de Umberto Giordano. Si bien el crítico consideró que el desempeño de los papeles principales no fue parejo, acerca de Singer apuntó:

... con una muy importante excepción. Ella fue la gratísima revelación de Miryam Singer como la mulata Bersi; habíamos quedado favorablemente sorprendidos con esta soprano en el Requiem mozartiano, pero ahora, en un género tan diferente nos mostró una nueva faceta de sus condiciones: voz caudalosa y bien manejada y expresividad escénica ('osservarla' como diría el Increíble) (Muñoz 1985).

En noviembre de 1985 y con un repertorio totalmente diferente al anterior, nuevamente Heinlein se refirió a Singer, a propósito de su interpretación en la Cantata BWV 106, Actus Tragicus, de Johann Sebastian Bach, en el decimotercer programa de la Orquesta Filarmónica de Santiago bajo la dirección de Juan Pablo Izquierdo: "El 'Actus Tragicus' contó asimismo con las privilegiadas voces de la contralto Carmen Luisa Letelier, cálida y emotiva en su profesión de fe; y la soprano Miriam Singer, quien hizo gala de sonoridad luminosa y gran poder expresivo" (Heinlein 1985 b).

Estas tres actuaciones grosso modo ilustran el tenor de los comentarios vertidos a lo largo de su carrera como cantante. Tempranamente, la crítica destacó la expresividad vocal y escénica, así como su dominio musical y, más adelante, a lo anterior se sumó la versatilidad en la interpretación de variados repertorios, el control vocal y seguridad en la afinación, la capacidad comunicativa y, paulatinamente, sus cualidades dramáticas.

En 1989, por ejemplo, el director germano Volker Wangenheim condujo un concierto de despedida junto con la Orquesta Sinfónica en el Teatro de la Universidad de Chile. El programa estuvo compuesto por los Sonetos de la muerte del compositor nacional Alfonso Letelier, obra escrita entre 1941 y 1948 con textos de Gabriela Mistral y la Sinfonía $n^{\circ} 1$ en do menor, op. 68, de Johannes Brahms. Junto con la acertada conducción de Wangenheim, Heinlein comentó sobre Singer en la obra de Letelier:

Poniéndose con cabal disciplina al servicio de la partitura, Miryam Singer cumplió sus difíciles obligaciones -jde memoria!- con pleno dominio y una voz parejamente redondeada y radiante, 
que resplandecía sobre el tapiz polifónico de la gran orquesta. Su dicción clara, su magnífica seguridad de entonación contribuyeron mucho al impacto artístico de las obras.

En los tercetos finales de estas poesías, la soprano alcanza un dramatismo sobrecogedor. Ojalá nuestra ópera nacional aproveche la emoción con la que Miryam Singer sabe llenar las 'venganzas hermosas' y el 'negro viento de la tempestad'. Fue, en suma, la mejor versión que hemos oído de esta exigente parte vocal (Heinlein 1989a).

En septiembre de ese mismo año interpretó "Summertime" y "My man’s gone now" de la ópera Porgy and Bess de George Gershwin, en un concierto de compositores norteamericanos de la Orquesta Sinfónica dirigida por su titular Francisco Rettig. Tanto la crítica de Pablo Meléndez (1989) como la de Heinlein (1989b) fue elogiosa:

"La soprano Miryam Singer exhibió una voz privilegiada, de material purísimo y timbre cautivador". Agregó que supo cómo llegar delicadamente al auditor por su penetración en el "meollo poético-musical", aun cuando este "no repare en su fonética culta del inglés, un tanto reñida con la pronunciación de los negros sureños" (Heinlein 1989 b).

A fines de 1989 la Orquesta Sinfónica, también bajo la dirección de Rettig, ofreció un interesante concierto de música del siglo XX compuesto por partes de la ópera Wozzeck de Alban Berg y de la ópera-oratorio Edipo Rey de Igor Stravinski. Tanto la crítica de Ítalo Passalacqua (1989) como la de Federico Heinlein (1989c) coincidieron en las cualidades vocales de Singer y en el alto nivel de interpretación de fragmentos de Marie de Wozzeck. No obstante, este último realizó dos consideraciones. Primero, volvió a llamar la atención acerca de las condiciones líricas de Miryam Singer para la ópera:

¿Cómo es que aún no se ha aprovechado sus enormes cualidades en nuestra temporada lírica? Su material hermoso, potente y entonado, de múltiple matiz está al servicio de una emotividad entrañable. Con disciplina musical controla cada factor del modo más notable, logrando esquivar incluso los peligros del sprechgesang... (Heinlein 1989c).

En segundo lugar, consideró inoportuna su inclusión en el cuadro final de voces infantiles, "cuando ya la suponemos acuchillada por Wozzeck" en esta tragedia de Berg (Heinlein 1989c). Aspectos como este, por ejemplo, fueron vivencias importantes que la animaron a incursionar como régisseur y, posteriormente, en la dirección.

A comienzos de 1990 Singer se trasladó a los tradicionales conciertos veraniegos de las Semanas Musicales de Frutillar. Daniel Quiroga (1990) comentó positivamente el programa vocal en el que Singer y Pilar Díaz interpretaron una selección de lieder románticos y un dúo de Cosi fan tutte de W. A. Mozart, más un dúo de La Traviata de Giuseppe Verdi cantado por Singer y Patricio Méndez, todo acompañado al piano por Hilda Cabezas (Quiroga 1990). En el ámbito sinfónico-coral, la apertura de la Temporada de la Orquesta Filarmónica de 1990 se realizó con una obra paradigmática: la Sinfonía $N^{\circ} 9$ en re menor, "Coral", op. 125, de Ludwig van Beethoven, dirigida por Maximiano Valdés, titular del conjunto. El sentido de espiritualidad y humanidad que proyecta la música así como aciertos y desaciertos de la batuta de Valdés (especialmente en los tempi) fueron plasmados por Heinlein (1990a) en su comentario. Junto con aplaudir el logro de Jorge Klastornick con el Coro Municipal y del cuarteto de solistas, el crítico destacó el "fiato formidable" del bajo estadounidense Stephen Saxon, "la luminosidad de nuestra soprano Miryam Singer" y "la firme defensa de las líneas centrales" a cargo de Carmen Luisa Letelier y José Azócar, contralto y tenor respectivamente (Heinlein 1990a). En otro concierto, dedicado a creadores germanos de la Orquesta Sinfónica de Chile, dirigido por Volker Wangenheim, otra vez este crítico reforzó su percepción de Singer. Acerca de la interpretación de la scena ed aria de concierto Ah pérfido spergiuro, de Beethoven apuntó: 
¡Cuántas facetas se le pueden descubrir a una interpretación de jerarquía! Esmeradamente secundada por Wangenheim y el cuerpo sinfónico, la soprano chilena Miryam Singer hizo una labor artística fenomenal.

Con autoridad de verdadera prima donna dominó, desde luego, cualquier aspecto de emisión. Más importantes aún fueron los múltiples matices expresivos, que comunicaban al oyente el furor y la congoja de un corazón desgarrado. El dramatismo de la entrega constituyó sin duda, el suceso más relevante de la velada (Heinlein 1990 b).

En el campo operístico, en octubre de 1990 Singer cantó el papel de Siébel en Fausto de Charles Gounod. Sobre la primera función, que cerró la Temporada Internacional del Teatro Municipal, Víctor Muñoz (1990) acentuó el buen trabajo de los integrantes chilenos del elenco, como Singer y Oscar Quezada. Sin embargo, no estuvo en total acuerdo con decisiones escenográficas y de iluminación del régie Roberto Oswald (Muñoz 1990).

En 1991 Miryam Singer tuvo roles en dos óperas de W. A. Mozart significativas para ella: Cosi fan tutte y La flauta mágica. Como se verá más adelante, para la primera hizo la régie paralelamente al rol de Fiordiligi cuatro años después y en 2013 la dirigió completamente. Con la La flauta mágica, aparte de cantarla, en 2006 efectuó un gran proyecto que involucró a tres universidades que se comentará más adelante.

La Temporada de Ópera internacional del Teatro Municipal 1991 se inauguró con Cosi fan tutte, con Singer en el rol de Despina. Las críticas de Ítalo Passalaqcua (1991a), Mario Cordova (1991) y Cardona (1991) fueron coincidentes en cuanto a la caracterización del personaje, el humor, la nitidez y musicalidad de su voz y la solidez dramática, cualidades que le permitieron llegar rápidamente al público. De La flauta mágica, también de la Temporada Internacional, Passalaqcua destacó el aporte del trío Miryam Singer, Adriana Muñoz y Carmen Luisa Letelier, "como las damas-hadas, graciosas, desenvueltas y vocalmente sólidas” (Passalacqua 1991b).

En cuanto a conciertos, cuatro de muy distinto repertorio reseñó Federico Heinlein en 1992, en los que recalcó el creciente desarrollo expresivo y las cualidades dramáticas de Singer. Tal es el caso de su interpretación del aria de concierto Ah pérfido spergiuro, op. 65, de Beethoven, del programa de verano efectuado en la Iglesia de San Francisco por la Orquesta Filarmónica de Santiago dirigida por Michelangelo Veltri (Heinlein 1992a). También, en la audición integral de Mortal mantenimiento del compositor nacional Carlos Riesco, aparte de elogiar su autonomía vocal, celebró "su denuedo y voluntad comunicativa ante esta música que -según dice ella- no obedece a patrones de ningún tipo" (Heinlein 1992b) y que fue secundada por un cuerpo instrumental de gran densidad a cargo de la Orquesta Sinfónica dirigida por Agustín Cullell, en el cuarto concierto de abono (Heinlein 1992b). Acerca de la Gran misa en si menor BWV 232 de Johann Sebastian Bach, a cargo de Juan Pablo Izquierdo con la Orquesta Sinfónica, un grupo del Coro Sinfónico (dirigido por Guido Minoletti) y solistas (entre ellos Singer), Heinlein (1992c), calificó la velada como "una entrega impresionante, que permanecerá como tesoro vivo dentro de quienes presenciaron esta gloriosa función en el Teatro de la Universidad de Chile" (Heinlein 1992 c). Finalmente, ese año Singer cantó en el estreno de Stabat Mater de Antonín Dvořák, en un concierto tributo al sesquicentenario de la Universidad de Chile efectuado por la Orquesta Sinfónica de la Corporación Cultural del Bío-Bío, el Coro de la Univesidad de Concepción y solistas dirigidos por Wilfried Junge. En esa ocasión el crítico (Heinlein 1992d) realzó a los cuatro solistas y de Singer: "Abunda la expresión lírica de los solistas vocales. Sobrecoge el esplendo de la soprano en 'O quam tristis' y su entrañable dúo con el tenor [Alejandro Prieto] ('Fac ut portem')” (Heinlein 1992 d). Es oportuno decir que también ese año actuó en la temporada internacional del Teatro Municipal de Santiago con el rol de Zaida (novia de Selim), en El Turco en Italia, drama bufo en dos actos de Gioacchino Rossini. En el elenco hubo solo dos cantantes nacionales: ella e Isaack Verdugo, todos bajo la dirección 
de Massimo de Bernart (Centro DAE 1992). Su ardua actividad musical fue reconocida con el Premio APES (Asociación de Periodistas de Espectáculos) a la mejor cantante tanto en 1992 como en 1994.

En los dos años que siguieron, 1993 y 1994, Singer tuvo el rol de la gitana Frasquita (1993) en Carmen de Georges Bizet, en la Temporada Internacional de ópera, junto con Orquesta Filarmónica de Santiago, el Coro Profesional del Teatro Municipal de Santiago y Coro de Niños Escuela Arturo Toro Amor, dirigidos por Miguel Patrón Marchand (Centro DAE 1993) y papeles protagónicos en dos óperas de Bellini y en una de Verdi. Además, cantó en distintas temporadas con repertorio como la Cantata $\mathrm{N}^{\circ} 106$ Actus Tragicus de Bach (Heinlein 1993a), los Poemas norteños de Ángel Lasala (Argentina), Nel dolce del obblío, de G. Frédéric Haendel (Heinlein 1993b), selección de lieder de Robert Schumann (Heinlein 1993c) y el Réquiem alemán de Johannes Brahms (Heinlein 1993d), entre otros.

En las óperas italianas Singer brilló en el bel canto. Daniel Quiroga (1993) elogió su "notable desempeño" en el rol de Elvira, en Los Puritanos, que presenta grandes dificultades, pero que ella abordó con propiedad y solidez musical otorgando humanidad a su personaje. También se refirió a su conexión con el público y a algunos momentos relevantes:

Porque su voz tiene la particularidad de llegar a la sensibilidad del auditorio. No es un mero computador de notas exactas. Si al comienzo se advirtió cierta timidez, a lo largo de la obra fue acentuando su presencia escénica y recibió aplausos luego de "Qui la voce soave", realizada con fina musicalidad, que llevó a brillante virtuosismo en "Vien Diletto, ganando cálido aplauso. En dúos y cuartetos obsequió más agudos que lo pedido y así su desempeño fue recibido con satisfacción creciente, por su seguridad y dominio, hasta el dúo final. Efectivamente, casi sin darnos cuenta, había una soprano chilena lírico-ligero capaz de dar brillo y personalidad a un rol de tanta responsabilidad como a Elvira Valton (Quiroga 1993).

Aunque Mario Córdova (1993) no consideró afortunado el resultado del estreno del segundo elenco del Teatro para Los puritanos de Vicenzo Bellini (27/8/1993), especialmente por el débil concurso de Oscar Imhoff en el rol de Arturo a causa de problemas en su voz, reconoció como un éxito la actuación de Miryam Singer en Elvira: "Convincente por completo en su papel, esta soprano chilena brindó una actuación magnífica. Tras un dúo inicial no del todo logrado, se dio para ella una sucesión de altos logros que fueron coronados por las más cálidas ovaciones" (Córdova 1993).

Amina, en La sonámbula de V. Bellini, fue otro de los roles que representó Singer en un programa del segundo elenco (nacional) de la Temporada de 1994, junto con los solistas Isaack Verdugo y Rodrigo Navarrete, entre otros, el Coro del Teatro Municipal y Orquesta Filarmónica de Santiago bajo la conducción de Miguel Patrón Marchand. Tanto Víctor Briceño (1994) como Mario Córdova (1994a) resaltaron el buen resultado de la función y, salvo detalles de orden vocal de algunos músicos, también la adecuada entrega de los solistas y de la dirección. Por otra parte, ambos coincidieron en el notable desempeño de Singer tanto en lo vocal como en la expresión dramática, rasgos que, como se ha visto, fueron acentuándose en sus actuaciones. Briceño apuntó que "su trabajo como Amina fue convincente y pudo manejar con sus capacidades las dificultades en la agilidad de vocalización que tiene la composición de Bellini” (Briceño 1994). Córdova, por otro lado, junto con recordar "el rápido ascenso en su carrera" y el exitoso resultado como Elvira en 1993, entre otros aspectos, dijo:

Mejorada en volumen, que en la zona sobreaguda se percibe algo incisivo, esta soprano enfrentó con máxima seguridad los constantes desafíos impuestos por el papel. Como lo son los pasajes de fioratura con ascenso y descensos demandantes, de una agilidad vocal extrema, que ella se empeñó siempre en sacar de adelante (Córdova 1994a). 
Si La sonámbula fue bien criticada, mucho más lo fue La Traviata de G. Verdi en su versión nacional en el Teatro Municipal (10/10/1994), tanto por el desempeño del elenco y la Orquesta Filarmónica a cargo de Miguel Patrón Marchand, como por la entusiasta recepción de público. Acerca de Singer, B.V. recalcó el trabajo vocal y dramático: "Es notorio que en su interpretación del rol hay un análisis del personaje y de sus características; eso le permite manejar su expresión corporal con sentido y alejarse del mecanismo que se produce cuando el rol no se asume en su integridad" (B.V. 1994). Córdova, además de lo anterior, fue algo más detallista en sus comentarios musicales:

Las “tres Violetas" que el público espera diferenciar en La Traviata fueron encarnadas de modo tan óptimo en lo vocal como convincente en lo teatral. La bravura de Sempre libera, en el primer acto, no opuso ninguna resistencia a un canto espléndido que dejó ver una vez más sus extraordinarias dotes para los agudos brillantes y la exigente filigrana. Luego, la frivolidad dejó a la emotividad del segundo acto, en el cual el dúo con el barítono [Patricio Méndez] alcanzó ribetes muy enternecedores. Pero fue el acto final el que vio a Miryam Singer desplegando la mayor batería de recursos, mediante una sucesión de grandes logros en Addio del passato y en el dúo Parigi o cara culminados con un aterrador Ah, gran Dio, morir si giovin (Córdova 1994 b).

Las críticas anteriores son una muestra que ratifican la razón por la que obtuvo el premio a la mejor cantante de ópera nacional de 1994, otorgado por Círculo de Críticos de Arte de Chile. Así, con este incentivo, Singer enfrentó en 1995 un nuevo desafío: su debut como régie, vestuarista e iluminadora, aparte de cantante en el rol de Fiordiligi en Cosi fan tutte de W. A. Mozart. Desde mi óptica, ese año y este hecho marcaron un punto de inflexión en su carrera para que, más adelante, definitivamente se aventurara en la dirección y producción de óperas.

Cosi fan tutte se programó para los Conciertos de Mediodía del Teatro Municipal. Como es sabido, este ciclo se ofrece a la hora de almuerzo o "colación", por tanto, el repertorio se ciñe a dicho tiempo. Por su extensa duración, se representó en dos días consecutivos, con los cortes necesarios para reducirla a una hora por jornada. Sobre la régie, vestuario e iluminación de Singer se comentará en el acápite siguiente, no obstante, en su rol como Fiordiligi, Quiroga (1995) y Córdova (1995) coincidieron en el alto nivel alcanzado y la entusiasta recepción del público. Sintéticamente, este último señaló: "Miryam Singer tuvo a su cargo el papel de Fiordiligi, cuya amplia tesitura no opuso problemas a un notable canto que confirmó un talento ya apreciado en responsabilidades pasadas" (Córdova 1995). Es importante recordar que en la temporada internacional 1991 de ópera, Singer tuvo el papel de Despina con grandes elogios, como se vio antes.

Como fue la tónica de su carrera, los tres años siguientes, 1996 al 1998, Singer abordó repertorio de concierto de distintas épocas, en algunos casos de obras bien conocidas para ella, aunque también fue nutrido en ópera romántica. Por ejemplo, en 1996 fue solista en la cantata italiana Nel dolce dell'obli y en el oratorio Baltazar, ambas de George F. Haendel, en conciertos ofrecidos en la temporada del Montecarmelo y en los organizados por la Fundación Beethoven, respectivamente. Asimismo, en 1997, con motivo del aniversario 148 de la Universidad de Santiago, cantó en la conocida Sinfonía $N^{o} 9$ de Beethoven junto con la Orquesta Clásica de la USACH (Escobar 1997), en el oratorio Salomón de G. F. Haendel, en el Teatro Oriente, bajo la dirección de Fernando Rosas y, en 1998, en el Réquiem de G. Verdi, dirigido por David del Pino (Heinlein 1998). En cuanto a óperas, en 1996 Singer actuó, por ejemplo, en El elixir del amor de Gaetano Donizetti, como Adina (Centro DAE 1996a), en Elektra de Richard Strauss con el rol de doncella (Centro DAE 1996b) y en Un baile de máscaras de Giuseppe Verdi como Paje Oscar, presentada en el marco de Encuentros con la Ópera del Teatro Municipal de Santiago (Quiroga 1996). Con elenco solamente nacional, el Coro del Teatro y la Orquesta Filarmónica de Santiago, bajo la batuta de Miguel 
Patrón Marchand, fue evaluada por Quiroga (1996) señalando "el resultado general como más que satisfactorio y, en ocasiones, plenamente ajustado al contenido".

Significativo para la ópera y para Singer fue el año siguiente. Por una parte, finalizó un ciclo wagneriano y, por otra, el estreno de una ópera nacional. Además, junto con el director Santiago Meza fueron reconocidos por la puesta en escena y dirección musical de Madama Butterfly de Giacomo Puccini (1997) por el Círculos de Críticos de Arte de Valparaíso (1997).

La empresa iniciada en 1994 por el Teatro Municipal de producir La Tetralogía (Anillo de los Nibelungos) de Richard Wagner completa, con una ópera por año, culminó en 1997 con El ocaso de los dioses. Se presentó en el marco de la Temporada Internacional, pero con la participación de cantantes chilenas, el Coro del Teatro y la Orquesta Filarmónica de Santiago dirigida por Gavor Otvös. La crítica reconoció el reto de producir la obra wagneriana, al mismo tiempo que destacó el correcto desempeño de cantantes, el coro, la orquesta y la régie, escenografía e iluminación de Roberto Oswald y de Aníbal Lápiz en el vestuario. Según Córdova (1997), "los esfuerzos desplegados por este centro artístico nacional bien valió la pena, pues la producción superó con creces toda expectativa” (Córdova 1997). En cuanto a las cantantes locales, expresó: "el otro trío femenino, el de las ninfas del Rhin, cuenta con los únicos elementos no importados del grupo de solistas, Miryam Singer [Woglind], Miriam Caparotta y Mariselle Martínez triunfan tanto en lo vocal como en la difícil y anfibia actuación que les asigna el libreto" (Córdova 1997).

El estreno en Concepción de la ópera El ahijado de la muerte, del compositor chileno Wilfried Junge con libreto de Jaime Fernández (10/10/1997), a mi juicio, también puede considerarse un acontecimiento en el ámbito de la creación nacional, porque, a diferencia de otros géneros, no es frecuente ni la composición de óperas ni su estreno. La ópera, producto de un proyecto Fondart, está basada en un cuento de los hermanos Grimm. Actuó la Orquesta Sinfónica de Concepción, el Coro de Concepción, preparado por Marcelo Vásquez, y el Conjunto de Danza "Orpiz", todos bajo la dirección general del conductor español Alexis Soriano (Editorial,C. 1998: 87). El rol de Miryam Singer fue El Arcángel, y según Quiroga (1997) "animó su mensaje desde la altura con su grato timbre". En un plano más general, según el crítico, "esta ópera se inscribe con mérito en la escasa producción nacional del género por su factura y lenguaje musical directo".

En 1998 nuevamente Miryam Singer hizo el rol de Violeta en La Traviata de G. Verdi junto con la Orquesta Filarmónica de Santiago, conducida por Miguel Patrón Marchand, en el marco del programa Encuentro con la ópera. En la ocasión, según V. M. (1998), Singer tuvo "una de las mejores actuaciones dentro de su variado repertorio", destacando su musicalidad y seguridad en "las notas más comprometidas". Según él, "interpretativamente recreó una variada gama de emociones dentro de una entrega intensa y cargada de intención" (V. M 1998). Quiroga, junto con referirse a su buen desempeño vocal y escénico, comentó acerca de su interés como régie, apuntando que "el teatro le llama con poderosa fuerza desde todos los ángulos (Quiroga 1998a)".

De un carácter totalmente diferente de la obra anterior fue El murciélago, opereta de Johann Strauss hijo, presentada en Encuentro con la Ópera del Teatro Municipal de Santiago, en septiembre de 1998. Singer en el rol de Rosalinde (esposa de Eisenstein) fue comentada por Quiroga (1998b) con las siguientes palabras: "Muy digna la Rosalinda, señora de Eisenstein, con Miryam Singer, marcando la diferencia social con su criada, aunque algo demasiado seria a veces. Vocalmente lució su versión de Czardas en el acto de la fiesta del Príncipe Orlowsky y en los dúos y concertados (Quiroga 1998b)”.

Es notorio que, a partir de 2000, Miryam Singer paulatinamente fue virando hacia otros proyectos, sin dejar por ello el canto. A mi juicio, se conjugaron algunos aspectos que pudieron influir en una diversificación de su actividad. Por ejemplo, y entre otros, ingresó 
como docente al Instituto de Música de la Pontificia Universidad Católica (2000) a cargo del Taller de Ópera, con el que ha montado sistemáticamente cuadros y óperas con estudiantes y músicos profesionales. Realizó la producción general, régie, diseño de vestuario y de escenografía para ciclos de conciertos o espectáculos musicales en distintos espacios institucionales y públicos del país. También efectuó algunos viajes profesionales, como el concierto "Zarzuela Gala Concert" ofrecido en Weill Recital Hall de Carnegie Hall, Nueva York (noviembre 2002) o el paso por México y Guatemala (2005 e inicios de 2006) para dar conciertos y formar parte del cover en la producción de Aída de G. Verdi en Guatemala (Corbella 2006: 98) o la invitación que recibió para dictar un taller en la Academia de Música y Danza de Jerusalem, Israel (2007) (López 2007: 93). Además, se aventuró a postular a proyectos nacionales de envergadura al Fondo de Fomento de la Música Nacional (2006, entre otros). No obstante, también hay constancia de su participación en conciertos de temporadas y óperas, como se muestra a continuación.

Daniel Quiroga (2000) informó acerca de un exitoso concierto en 2000 con una selección de la ópera Porgy and Bess de G. Gershwin con los solistas Miryam Singer y Lawrence Craig (norteamericano), junto con el Coro Sinfónico de la Universidad de Chile y la Orquesta Sinfónica bajo dirección de David del Pino (Quiroga 2000). El mismo crítico dio cuenta en 2001 de la interpretación del Réquiem de G. Verdi en el Teatro de la Universidad de Chile. Junto con recordar la profunda expresividad de la obra y las dificultades vocales de la partitura que, a su juicio, fueron bien resueltas, observó el profesionalismo del coro, la orquesta y solista, entre ellos Miryam Singer y Pilar Díaz, que sortearon con expresividad las "arriesgadas" exigencias musicales (Quiroga 2001). También participó Singer como solista en Stabat Mater, de Giovanni B. Pergolesi, en un concierto de la Orquesta de Cámara, dirigida por Alejandro Reyes, en la Parroquia Nuestra Señora del Rosario y en el Teatro Municipal de Nuñoa (abril de 2003) (Corbella 2003: 113) y actuó en el rol de recitante en el estreno en Chile de Chanson de Bilitis de Claude Debussy, dirigida por Zsolt Nagy (Hungría), en el marco del Ciclo de Cámara IMUC 2008 (López 2008: 103).

En el campo de la ópera, entre 2000 y 2005 aproximadamente, el Teatro Municipal fue su casa principal, aunque paulatinamente alejándose para ocuparse de la producción y dirección. No obstante, entre otros, actuó en roles como Vitellia en La Clemenza di Tito de W.A. Mozart en 2000, Alice Ford en Falstaff de G. Verdi en 2001, Margarita en Mefistofele de Arrigo Boito, Primera dama en La flauta mágica de W.A. Mozart en 2002 y Floria Tosca, en la ópera homónima de G. Puccini en 2005, en la que además fue régiejunto con el director David del Pino.

En general, los críticos de las últimas actuaciones como cantante fueron laudatorios acerca de la interpretación de Singer en los diversos papeles, la calidad y precisión vocal y sus dotes dramáticas, imprimiendo a cada personaje el carácter adecuado. Junto con esto, también se reiteró su capacidad comunicativa con el público. Por ejemplo, para Juan Antonio Muñoz (2000), Vitellia es el papel "menos cuidado de todos en términos dramáticos y su proceder es incomprensible [... pero], la artista chilena le dio a eso una vida más compleja y reflexiva” (Muñoz 2000). Sobre la última función nacional de 2001 de Falstaff de G. Verdi en el Teatro Municipal, Muñoz (2001) destacó la régie de Michael Hampe, la mano firme de la dirección de Rodolfo Fischer y la adecuada respuesta del cuerpo solista. Llamó la atención sobre "Patricio Méndez, con su voz en forma y su manera de decir la palabra verdiana y Miryam Singer (Alice Ford), excelente actriz, con registro agudo glorioso y conduciendo la situación musical en plenitud" (Muñoz 2001). No tan afortunada fue la puesta en escena de Mefistofele de Arrigo-Boito en 2002, según Muñoz (2002). Comentó la errada perspectiva del trabajo escenográfico y de régie de Antonello Madau-Díaz, pero sí apreció la excelencia del Coro del Teatro Municipal, el trabajo con la orquesta y el cuidado que tuvo con el cuerpo solista Rodolfo Fischer y el Coro de la Escuela de Niños Arturo Toro 
Amor. Dijo que "Margarita no solo salvó a Fausto sino a 'Mefistófeles'. La soprano Miryam Singer derrochó expresividad y demostró ser una gran intérprete" (Muñoz 2002). Ese mismo año (y también en 1991) fue una de la damas en La flauta mágica del elenco internacional del Teatro Municipal. A Gutiérrez (2002) le pareció "la más homogénea y fiel al estilo mozartiano que hemos escuchado para esta ópera en nuestro país". Manifestó que todos los artistas cumplieron su rol a cabalidad, pero destacó "especialmente los tríos de damas y genios, cuyas hermosas escenas tuvieron la homogeneidad y musicalidad exigidas por el autor (Gutiérrez 2002). Acerca de Tosca, en 2005, se comentará en la siguiente sección.

Con un amplio y heterogéneo repertorio interpretado desde su debut en Chile en 1984 y hasta 2009, Miryam Singer se despidió de su carrera como cantante en la que fuera su casa por tantos años, el Teatro Municipal, interpretando Cuadros de la colección privada de Dios, del compositor Aharon Harlap, bajo la dirección de Víctor Alarcón, maestro que lo acompañó en numerosos proyectos. A partir de entonces, Singer se dedicó enteramente a la docencia, la producción de ópera y a la gestión en las artes.

\section{DE CANTANTE A RÉGIE}

Paralelamente a la carrera de cantante, a partir de 1995 Singer comenzó una trayectoria como realizadora, directora, diseñadora de escenografía y vestuario de ópera, como se adelantó más arriba. Hacia 2010 su dedicación a esta actividad fue total, con un número significativo de trabajos, siempre manteniendo presente su objetivo de llegar con la ópera a un vasto público, incluyendo niños.

Si bien el oficio de régie de ópera ha contado con numerosas celebridades, una aleatoria revisión da cuenta que no son demasiadas las mujeres que han ejercido esta responsabilidad, al menos en la ópera. En su caso, Miryam Singer declara que así como no tuvo un referente específico en este campo, tampoco considera que encontró escollos para realizarse en sus propósitos por su condición de mujer. Comenta acerca de las únicas dos veces en que no pudo conseguir lo que quería: cuando solicitó realizar una práctica de arquitectura en una obra de construcción, ya que a los maestros no les gustaba que una mujer los dirigiera; y otra vez que, aconsejada por su maestra, audicionó en Alemania. En esa ocasión, al presentarse y manifestar que lo hacía para La Traviata (Violeta), el encargado de las inscripciones la miró y le dijo: "No, muy chica. Gilda". Con humor reafirma: "efectivamente soy muy chica, mido 1,55 m" (Peña 2021). Aunque ese episodio la afectó, también comenta que esa es una realidad. Vale decir, una carrera puede limitarse a ciertos roles que, aunque son "maravillosos", al cumplir cierta edad ya no se puede continuar cantándolos porque son para una voz más bien joven, como Despina o Susanna (de Cosi fan tutte y Las bodas de Fígaro, respectivamente). Por otra parte, por entonces, ya no quería interpretarlos, porque sabía que su instrumento vocal podía dar más y ya estaba en papeles como Violeta o Elvira. "Si yo me hubiese quedado en Europa, con un sistema de contratación típica [como cantante] no habría llegado ni a la dirección de ópera ni habría podido asumir esos roles que te decía [La Traviata, por ejemplo] por mi estatura" (Peña 2021).

La anécdota anterior, en parte, se vincula con la decisión de encauzarse hacia la dirección, pese a que, según señala, no tiene una personalidad que se proyecta demasiado en el tiempo: "soy de aquí y ahora", afirma; por tanto, no pensó ni planeó con anterioridad esa alternativa. Sí recuerda que siendo cantante hubo muchos régisseurs de renombre que la dirigieron y no siempre concordaba con sus decisiones. "Yo fui aprendiendo en el propio hacer; más bien por oposición ... dándome cuenta de lo que me parecía que no debía hacerse". Dice que miraba, observaba y pensaba cómo debiera ser la puesta en escena, pero "yo no tenía referentes... Uno va a ver ópera en otros países y ve de todo... muy malo y cosas increíbles...” (Peña 2021). 
Con grandes expectativas puestas en la régie, varios roles de ópera a su haber, experiencias personales como espectadora, amante del cine y del teatro y, como arquitecta, con una clara visión del espacio, las materialidades, la función de la luz y otros componentes propios de la arquitectura, se presentó la oportunidad que, al mismo tiempo, fue un desafío. Eduardo Browne Puga la invitó a cantar en 1995 el rol de Fiordiligi, en la ópera Cosi fan tutte de W. A. Mozart en el Teatro Municipal de Santiago; junto con aceptar, ella le propuso hacerse cargo de la dirección, el diseño de escenografía y vestuario y la iluminación. "Yo tenía la absoluta certeza que lo iba a hacer bien. Primero, respetuosamente con los cantantes (...) y, segundo, con una lógica teatral que nadie traía” (Peña 2021).

Con esas convicciones, su debut en ese campo se caracterizó por una puesta en escena que se trasladó temporalmente a nuestros tiempos y con recursos escenográficos y decorativos simples. Como se vio antes, la crítica como cantante fue estimulante, pero también lo fueron los comentarios acerca de la régie. Para Córdova (1995), entre otros aspectos, fue un acierto traer la ópera al tiempo presente sin afectar la línea argumental, destacando los roles de Ferrando, Giulielmo y Despina. Culminó su comentario apuntando: "Este Cosi fan tutte fue una experiencia inolvidable, merecedora de todo elogio, en la que el talento de Miryam Singer, verdadera madre del proyecto, demostró que un ingenio desbordante puede primar por sobre la escasez de recursos, consiguiendo un resultado magnífico" (Córdova 1995).

Entre ese primer reto y su siguiente trabajo pasaron diez años en los que siguió cantando. En 2005, la programación de Tosca de Puccini en una versión de concierto le brindó la posibilidad de asumir el rol de Floria Tosca y de realizar la régie junto con David del Pino Klinge, director de la Orquesta Sinfónica de Chile. Las funciones se efectuaron en el Teatro de la Universidad de Chile y en el Aula Magna de la Universidad Federico Santa María en Valparaíso. En su crítica, Francisco Gutiérrez (2005) destacó las fortalezas de Singer: "una cantante-actriz de gran sensibilidad dramática y de singular musicalidad expresiva", cualidades que se evidencian en la construcción de Floria Tosca. Aunque le pareció que el rol no es "totalmente adecuado a sus características vocales", convino en que "su concepción dramática revela cierta originalidad al presentarnos a Floria como una mujer de arranques emocionales intensos, pero básicamente refinada y de cierta debilidad que a mitad de la acción dramática la tiene prácticamente destruida interiormente". También destacó la acertada interpretación del dúo con Mario [Cavaradossi] en el tercer acto, lo mismo que la escena final (Gutiérrez (2005). Acerca de la régie, Gutiérrez reconoció el desafío y la dificultad de abordar una obra dramática en versión de concierto y, por otra, admitió la acertada escena final del suicidio de Tosca, en la que "toda la dramaticidad fue expresada a cabalidad en una intensa dirección orquestal" (Gutiérrez 2005). No obstante, no compartió del todo algunas decisiones que permitieran conservar la unidad dramática de la acción, como recurrir a "casi los mismos efectos de una actuación normal con un espacio de actuación muy reducido, como los enfrentamientos entre Tosca y Scarpia de todo el segundo acto" (Gutiérrez (2005).

No obstante lo anterior, las aspiraciones de Singer eran mayores y buscó mecanismos para darle curso a sus propósitos: en un plano general, masificar la ópera, llevarla a distintos espacios y lugares del país y, en lo más específico, involucrar y trabajar este género con niños. Dos grandes desafíos que se impuso en 2006 apuntaron hacia esa dirección, ambos con óperas de Wolfgang Amadeus Mozart: La flauta mágica y Las bodas de Fígaro.

Para alcanzar el primero, en conjunto con Eduardo Browne postuló al Fondo de Fomento de la Música Nacional con el proyecto "Los niños de Chile cantan La Flauta Mágica de Mozart”, en el que la Ópera de Cámara UC dirigida por Singer hizo una gira de siete funciones por diferentes colegios de la Región Metropolitana y de la VI Región (Corbella 2006: 85). La particularidad fue que incorporó a los niños de los coros de los colegios como actores cantantes con vestuario, maquillaje y trajes en sus escenas. El 
hermoso documental Los niños de Chile cantan la Flauta Mágica da cuenta de ello (Singer 2006). Esa experiencia fue reveladora y la ha acompañado desde entonces, a tal punto que, en una entrevista reciente para radio Beethoven, reafirmó su interés e intención de trabajar con niños e incluso expresó su deseo de comenzar un movimiento como Crecer Cantando, que lideró Víctor Alarcón, pero en este caso un Crecer Cantando con la Ópera. Recordando esa vivencia comentó:

...vi situaciones en el tiempo real en las cuales yo me pude percatar cómo la posibilidad de participar en una experiencia de esta naturaleza modificaba la relación de los niños consigo mismos. La sensación que daban de ser personas que se iban empoderando. Como yo lo fui ensayando, visitaba al coro del colegio cada tanto tiempo, y me iba dando cuenta de cómo esos niños iban sufriendo una transformación muy positiva hasta llegar al escenario, y de la experiencia misma salían eufóricos. Igual que sus padres (cit. en De la Sotta 2021).

Las bodas de Fígaro, por su parte, fue un proyecto orientado hacia el primer objetivo, desarrollado bajo el alero universitario y que tuvo impacto en la comunidad capitalina. Se presentó en el primer concierto del XLII Ciclo de Música de Cámara del Instituto de Música de la Pontificia Universidad Católica de Chile, en el Aula Magna del Centro de Extensión UC $(8 / 6 / 2006)$. La dirección general, régie, escenografía y vestuario estuvo a cargo de Miryam Singer y contó con la participación de la Ópera de Cámara UC, la Orquesta de Cámara UCV dirigida por Pablo Alvarado, el Coro de Cámara UC dirigido por Mauricio Cortés y Juan Edwards en clavecín (Corbella 2006: 90). Al día siguiente (9 de junio), el Instituto de Música junto con la Corporación Cultural MetroArte del Metro de Santiago invitaron a presenciar la ópera, por primera vez, en el Metro Estación Quinta Normal, línea 5. Fue un espectáculo sin precedentes, al que asistieron más de 4000 personas (Metro de Santiago 2006). Asimismo, el elenco se presentó en Teatro regional de Talca ( 8 y 9 de septiembre) y en el Colegio Municipal People Help People de Santo Domingo (17 de septiembre 2006) (Corbella 2007: 79).

Esta ópera tuvo impacto en el medio capitalino y el Círculo de Críticos de Arte de Chile lo reconoció, otorgando el Premio de la Crítica "Distinción Especial 2006", en la especialidad de Ópera Nacional, a Las bodas de Fígaro producida por Extensión del Instituto de Música y la dirección general de Miryam Singer (Corbella 2007: 71). Con esta estimulante distinción, nuevos proyectos se concretaron en los años que vinieron. Por ejemplo, en 2007 Singer fue régie en una versión escénica ofrecida en el Centro de Extensión UC de Pierrot Lunaire de Arnold Schoenberg, con Nora Miranda, cantante y actriz, y el Ensamble Contemporáneo, dirigido por Aliocha Solovera (Singer 2007); en 2008 tuvo una cargada agenda, en la que, junto con sus actividades docentes, nuevamente una ópera de Mozart la mantuvo atareada, a lo que se sumó, a comienzos de 2009, el Primer Festival de ópera de Cámara.

El rapto en el serrallo de W. A. Mozart fue el resultado de un proyecto de producción de Miryam Singer, en el que tuvo además a su cargo la dirección, régie y diseño de escenario de la ópera. Con éxito se presentó en el Centro de Extensión UC y en la Universidad de Santiago (ambas en septiembre) con la Orquesta Clásica USACH dirigida por David del Pino. No obstante, la ópera se repuso en el marco del Primer Festival de Ópera de Cámara en enero de 2009, esta vez en la Plaza de Armas de Santiago, contando con cerca de 6000 espectadores (Ponce 2009). La organizó el Instituto de Música de la UC, con aportes de CCU y Fondart, y participaron el Coro Crecer Cantando, dirigidos por Víctor Alarcón, junto con la Orquesta Clásica de la USACH bajo la batuta del maestro David del Pino (Letelier 2009).

Tanto el Festival como dicha reposición se concretó gracias a que Singer se adjudicó un Fondo Nacional de Desarrollo Cultural y las Artes Fondart Bicentenario 2008-2009. El proyecto fue idea suya y se tituló "Asociatividad para el fomento de la ópera de cámara en Chile, Festival de Ópera de Cámara” e involucró a estudiantes y profesores de las escuelas 
de música de la Pontificia Universidad Católica de Chile y de la Universidad de Chile, así como a la Orquesta Clásica de la Universidad de Santiago. Fue un evento significativo para la ópera, para el quehacer musical universitario y para Singer. Acerca de las conversaciones iniciales, Hanns Stein, académico del Departamento de Música de la Facultad de Artes de la Universidad de Chile, expresó: "Creemos que es una excelente iniciativa reunir a todos quienes estamos trabajando en esto, para realizar algo en conjunto en vez de estar compitiendo entre nosotros (Comunicaciones de la Facultad de Artes 2009)". En efecto, el mismo comunicado de esa Facultad informó que parte de los objetivos "busca, entre otras cosas, mejorar el acceso de públicos masivos a la ópera, asociar los elencos de las tres universidades para formar redes y fortalecer las competencias profesionales de cada una de las agrupaciones musicales que participan en el proyecto, y convertirse en un espacio de acogida para jóvenes artistas (Comunicaciones de la Facultad de Artes 2009)".

El Festival fue coordinado por Miryam Singer y se programaron cuatro obras para los días 13, 17, 18, 28 y 29 de enero de 2009 en el Centro de Extensión UC. La Universidad de Chile presentó la Cantata del café BWV 211 de J. S. Bach en una versión para escena y la ópera Brundibár de Hans Krása, ambas producidas por Hanns Stein y traducidas al castellano por él y su esposa Choly Melnick ${ }^{1}$. Las dos producciones de Singer junto con la Ópera de Cámara UC fueron El rapto en el serrallo de Mozart, como se dijo, y Orfeo de Claudio Monteverdi. En la primera, además, estuvo la Orquesta Clásica USACH, el Coro Crecer Cantando y, el Coro de Estudiantes UC. En la segunda, junto con este último, la Orquesta de Cámara UC y Danzas Antiguas Universidad de Chile.

La crítica de prensa al primer Festival celebró la idea de reunir a las universidades en un espectáculo de calidad así como la cálida recepción del público. Acerca de la régie y el diseño escénico de Singer para El rapto en el serrallo, Muñoz [2009] fue entusiasta en sus comentarios, lo mismo que para el desempeño de la Orquesta Clásica USACH dirigida por David del Pino, el cuerpo de solistas y los coros arriba mencionados. Destacó "una puesta en escena jugada, libre, popular, sin atarse a ningún convencionalismo" y el apoyo de las tres pantallas gigantes, en una realización audiovisual "que comenta la trama haciendo una mixtura entre los paisajes en que la obra se desarrolla, los personajes, sus corporizaciones modernas, sus afectos y los ensayos de la ópera misma” (Muñoz [2009]). Singer es más específica respecto del uso y contenido de la tecnología: "A mí me parecía insuficiente el libreto de Johann Gottlieb Stephanie, yo quería contar muchas más historias, hacer un juego de planos" (Peña 2021). De este modo, en las pantallas se proyectan "historias filmadas con recuerdos, evocaciones, sueños y deseos de los personajes" (Singer 2009). Paralelamente, su intención con la plataforma audiovisual fue acercar al espectador a la ópera, "volviendo este género más accequible a la sensibilidad contemporánea" (Singer 2009). Nuevamente su trabajo con esta ópera fue reconocido con el Premio de la Crítica otorgado por el Círculo de Periodistas de Chile.

En cuanto al estreno de Orfeo, que cerró el Festival, la crítica aplaudió la versión escénica completa y el alto resultado musical. La producción, iluminación, vestuario, escenografía y régie fue obra de Miryam Singer y participó la Ópera UC, Orquesta de Cámara y Coro de Estudiantes UC, un octeto de bailarines de la Universidad de Chile y profesionales como Patricio Sabaté en el rol de Orfeo, entre otros, todos bajo la dirección musical del argentino Juan Manuel Quintana. Junto con elogiar a los cuerpos musicales y solistas, Córdova (2009) dijo que el montaje "fue una verdadera clase de austeridad e inteligencia", agregando que

1 Comunicaciones de la Facultad de Artes. Facultad de Artes se hace presente en Primer Festival de Ópera de Cámara (5 enero de 2009). https://www.uchile.cl/noticias/49300/fac-de-artes-se-hacepresente-en-primer-festival-de-opera-de-camara [acceso: 13 de diciembre 2021] 
se caracterizó por ser "minimalista, muy honesto, donde la carencia de elementos corpóreos fue muy bien suplida por la disposición y movimientos de los solistas, el decisivo coro y los bailarines". Sintéticamente, lo catalogó como un espectáculo de primer nivel, al que tuvieron acceso casi 2000 personas gratuitamente (Córdova 2009).

Un valioso e ilustrativo testimonio que reseña el proceso de producción de todas las obras del primer Festival es el documental "Abriendo la cortina de... Festival de Ópera de Cámara”, cuya dirección, producción, guion, edición y conducción también fueron de Miryam Singer. Se transmitió por Canal 13C (en diciembre de 2009 y marzo de 2010) (Subiabre 2010: 82) y está disponible en YouTube (Singer [2008]). Es importante decir que "Abriendo la cortina de..." consta de cuatro ediciones apoyadas por Fondart, del Consejo Nacional de la Cultura y las Artes, en el marco del proyecto Asociatividad para el Fomento de la Ópera en Chile, liderado por Singer. Los otros programas disponibles son La médium de Gian Carlo Menotti y La sugestión de Pablo Garrido en un mismo capítulo, Der Kaiser von Atlantis, de Viktor Ullman, ambos en 2011, y Renca, Paris y Liendres, ópera de Miguel Farías, en 2012.

También en 2008, Singer se encargó de la producción de la ópera de cámara La serva padrona, con música de G. B. Pergolesi, en el Salón Fresno de la Universidad Católica (Pontificia Universidad Católica de Chile 2010). El programa de mano, firmado por Singer, no solo contextualiza este intermezzo desde la perspectiva musical, sino también del ámbito social de la época, en la que el universo burgués y popular convergen a finales del siglo XVIII. Además, se encargó de comentar la puesta en escena que rescata "algunos giros clásicos de la commedia dell'arte" y una acción que "se ubica en un escenario inspirado en el eclecticismo del arte del grafiti y el diseño urbano actual” (Singer 2009). Acerca de la presentación, Juan Antonio Muñoz apuntó:

La puesta de Miryam Singer -responsable del diseño escenográfico, de la iluminación, el vestuario y la régie- tiene un look pop colorinche, atractivo para el público, con guiños a la producción cinematográfica chilena actual: un gran retrato de la actriz Catalina Saavedra en su papel en "La nana", preside la escena. Singer saca lustre a todo y aquí saca luces a su ingenio en el encuentro de recursos, pero también da en el punto justo para dar cuenta de cómo "La serva padrona" establece una trama cruzada de conflicto social, político y amoroso, en este aparentemente sencillo e inocente juego en el que Serpina intenta abandonar su situación de empleada puertas adentro para conseguir una cuota doméstica del poder al interior de un hogar pequeño burgués (Muñoz 2009).

La intensa actividad realizada por Singer en 2008 la hizo merecedora del Premio de la Crítica, entregado por el Círculo de Críticos de Chile por el montaje de Orfeo, de Claudio Monteverdi con la Ópera UC en el Salón Fresno, y del Premio Domingo Santa Cruz de la Academia Chilena de Bellas Artes del Instituto de Chile. Este último compartido con Eduardo Tironi, director de ARTV, por la serie audiovisual Maestro de la música, otra mirada a la música chilena, acerca de seis compositores nacionales (Pontificia Universidad Católica de Chile 2010). El programa contó con el apoyo del Consejo de Fomento de la Música Nacional, dependiente del Consejo Nacional de la Cultura y las Artes, fue emitido por ARTV y circuló públicamente como video.

Con posterioridad a 2009, año de despedida de su carrera de cantante, la producción de Miryam Singer fue en aumento, al mismo tiempo que asumió la responsabilidad de la Dirección de Artes y Cultura de la Vicerrectoría de Investigación de la Pontificia Universidad Católica de Chile en 2010. Desde ese cargo también ha impulsado la ópera tanto al interior de la propia institución como su proyección a la comunidad nacional. De la extensa lista de producciones de esta etapa se ilustrará algunas de ellas.

En el marco del $2^{\circ}$ Festival de Ópera de octubre de 2010, se presentó Don Pasquale, de G. Donizetti. Singer se encargó de la producción general, dirección, diseño escenográfico, 
vestuario e iluminación. Actuaron la Opera UC más solistas invitados, la Orquesta Sinfónica Nacional Juvenil dirigida por José Luis Domínguez y el Coro de Estudiantes UC. Como en el festival anterior, el evento fue otra etapa del proyecto Fondart Asociatividad para el Fomento de la Ópera en Chile, en el que participaron la Pontificia Universidad Católica de Chile, Universidad de Chile, Universidad de Santiago (USACH), a las que en esta ocasión se unieron la Universidad de Talca y la Universidad de La Serena. Acerca de esta ópera, Córdova (2010) destacó el buen partido que Singer le sacó al lugar, al escaso presupuesto y a los buenos cantantes que escogió para este montaje. Entre otros aciertos comentó: 'Este 'Don Pasquale', muy moderno y colorido en lo visual, optó por una mirada cercana al mundo de la historieta y el comic, que en nada descontextualizó la obra. Muy por el contrario, cargado de mucha gracia, tuvo el acierto de instalarlo en nuestra cotidianidad" (Córdova 2010). Además, el crítico informó que la producción se repetiría el 8 de enero de 2011 en la Quinta Vergara de Viña del Mar, en el marco de la Temporada de Conciertos de Verano de la Fundación Beethoven².

Otro resultado del proyecto antes mencionado fue el estreno en nuestro país de Der Kaiser von Atlantis o la Abdicación de la muerte (1943), ópera compuesta por Viktor Ullmann durante su cautiverio en el campo de concentración de Terezin. Se ofreció en el Centro de Extensión UC en septiembre de 2011, a cargo de la Ópera UC dirigida por Miryam Singer y la Orquesta de Cámara UC, con Francisco Rettig como director invitado. Singer fue la autora de la idea, la régie, la dirección audiovisual, el diseño y la iluminación. Es un drama que asombra, conmueve y, por qué no, horroriza. Por algo el afiche advierte que no es apto para menores. El dramatismo se acentúa por una puesta en escena en donde la orquesta se ubicó al centro de la sala, el público a su alrededor y los personajes cantaban desde cinco puntos cercanos a la orquesta. Colgando desde un columpio había otro personaje, más diez pantallas que proyectaban la traducción del texto y, como bien describe Muñoz (2011), "ilustran los contenidos de la obra con imágenes originales de la guerra, escenas teatralizadas de la vida que algunos personajes sueñan o recuerdan, el pavor de las cámaras de gases y los hornos crematorios" (Muñoz 2011). Con sonoridades expresionistas, por momentos atonales y con guiños a la música de cabaret (¿Kurt Weill?) y Mahler, entre otros recursos, según Ponce (2011): "estamos frente a una obra, que plantea una cuestión Ética, entrelazada con la Estética, transformándola en una obra de Arte superior" (Ponce 2011). Por esta producción, Singer volvió a obtener el Premio de la Crítica otorgado por el Círculo de Periodistas de Chile.

En 2012 Miryam Singer produjo Le convenienze ed inconvenienze teatrale de G. Donizetti, también parte del proyecto Asociatividad para el Fomento de la Ópera en Chile, en la que hizo la régie, escenografía y vestuario, contando con el elenco de Ópera UC, el Coro UC, la Orquesta de la USACH dirigida por Pablo Carrasco y un grupo de la Escuela de Danza de la Universidad de Chile. Esta farsa operística, que se presentó en el Centro de Extensión UC en agosto de ese año, se burla de los cánones de la ópera, sus personajes y situaciones. Según Córdova (2012), fue un acierto debido a que de por sí es ingeniosa y creativa, a lo que se sumó el trabajo de Singer a partir del "traslado de la acción a nuestro tiempo, la exacerbación de la farsa y la inclusión de números extras, acción que la obra permite”. A su juicio, los tres factores fueron fortalezas que "permite [n] conquistar a nuevos públicos" (Córdova 2012). Pero no solo el público adulto ha podido disfrutar de la ópera; también realizó dos producciones para el programa "Pequeño Municipal”, iniciado en 2005, con

2 En el sitio web de Miryam Singer, "Obras completas", se encuentra fechada en 2013, no obstante, por los títulos, la puesta en escena y los cantantes de la versión disponible en YouTube (https://www. youtube.com/watch? $\mathrm{v}=\mathrm{pHJqcolTd} 3 \mathrm{w} \& \mathrm{t}=1883 \mathrm{~s})$, se infiere que podría tratarse de un error en el sitio. 
el fin de llegar a un público familiar y escolar por medio de espectáculos variados y atractivos de ballet, conciertos y ópera. Primero, puso en escena la Historia del soldado de Igor Stravinky, obra que realizó en 2008, esta vez adaptándola para niños de modo que resultara llamativa para ese público (Lennon 2012a). El título siguiente fue El retablo del Maese Pedro de Manuel de Falla. Singer, en la producción artística, buscó nuevamente apoyo en la tecnología: "Fabricamos un retablo digital y para ello un equipo confeccionó cada uno de los títeres. Luego de ensayar cada movimiento de los muñecos, filmamos las marionetas sobre fondos pintados" (Lennon 2012b).

A partir de 2013, la alianza entre Miryam Singer y Eduardo Browne, iniciada en $1995^{3}$, se hizo más recurrente y la comunidad de intereses los ha mantenido unidos en varios proyectos. Entre ellos, destaca la producción de seis óperas para el Teatro Municipal de Las Condes. La primera que puso en su escenario dicho teatro, abierto al público en 2010, fue Cosi fan tutte (2013) de Mozart. Se programaron diez funciones y participaron dos elencos alternados. Singer tuvo a su cargo la dirección de escena, el diseño de escenografía, video, vestuario e iluminación, mientras Browne asumió la dirección de la orquesta, compuesta por diez músicos. Asistieron cerca de 5000 personas (Lennon 2014a). La crítica coincidió en el alto nivel alcanzado, tanto desde la perspectiva musical como en la dirección y puesta en escena de Singer, aun cuando la extensión se redujo respecto de la versión original. Hubo consenso en el excelente desempeño de las y los jóvenes cantantes y elogios para el resultado del grupo instrumental bajo la dirección de Browne. Respecto del trabajo de Singer, Córdova (2013) hizo notar que una vez más plasmó "su sello inagotable e inconfundible de creatividad, herramienta que solo ella pareciera saber manejar en nuestro medio para presentar óperas en forma atractiva y con recursos limitados" (Córdova 2013). También acotó que en un teatro como ese, bien implementado y con un "generoso escenario", utilizó pocos elementos, "pero con una gran pantalla curva posterior, sobre la que se proyectan múltiples imágenes de ambientación y también se funde realidad y fantasía virtual" (Córdova 2013). Acerca de esto último, en un reportaje, Singer adelantó que, además de proyecciones como lo hizo en sus últimas producciones, "incoporaré elementos del teatro Kabuki: un grupo de actores vestidos de negro, en un elemento muy teatral. Los actores encarnan una conciencia externa dentro de la acción. Son personajes que a veces transitan en la periferia, y otras intervienen en la trama" (cit. en Lennon 2013).

Lo anterior se comprende bien a la luz del comentario que escribe la propia Singer en el programa de mano, que refleja algunas de las preguntas o problemáticas que la movilizan a la hora de afrontar la dirección de una ópera. En este caso, apunta que una de ellas es que "Così fan Tutte pone el acento en la dificultad de reconocer la realidad objetiva y actuar consecuentemente". Así, a partir de una reflexión de ciertas claves que contiene la ópera, entre otros aspectos, declara que "propone una lectura de las materias fundamentales de Così: la estructura de la psiquis humana y la organización de las relaciones sociales" (Singer 2013).

El siguiente título ofrecido en el Teatro de la Municipalidad de Las Condes fue Madama Butterfly (2014) de Puccini, producido por Miryam Singer y Eduardo Browne, como el anterior. En seis fechas, la ópera fue protagonizada por Verónica Villarroel en el rol de Cio-Cio-San, representando por primera vez este rol en Chile, junto con su hermana Maribel, que según Singer, "si bien viene del mundo de la música popular, tiene un talento impresionante" (Lennon 2014a). A diferencia de Cosi fan tutte, no hubo cortes de ninguna

3 El vínculo data de 1995 cuando Singer tuvo el rol de Fiordiligi y, al mismo tiempo, se hizo cargo de la dirección, el diseño de escenografía y vestuario y la iluminación de Cosi fan tutte, en el Teatro Municipal de Santiago, como se ha dicho más arriba. 
escena. Singer comentó que su propuesta escenográfica es más bien de "espíritu minimalista" y, en este caso (distinto a anteriores), "El elemento audiovisual no será protagonista sino un complemento de la estética que intenté plasmar". Como amante de la cultura y el arte japonés, buscó inspiración en "la pintura nipona del siglo XVIII, en sus grabados y en el arte de las estampas" (cit. en Lennon 2014a).

Ese mismo año, Singer hizo su debut como régie en la Temporada Lírica Internacional del Teatro Municipal, con La flauta mágica. El elenco estuvo encabezado por la soprano alemana Anett Fritsch y el tenor puertorriqueño Joel Prieto, más la Orquesta Filarmónica dirigida por Konstantin Chudovsky. Lúdica, fantástica y colorida fueron rasgos que la destacaron, secundada por la tecnología, como ya lo venía haciendo en otras óperas. $\mathrm{Al}$ respecto ella precisó:

Yo trabajo (...) con una caja negra, y con proyecciones, que exhiben acuarelas de mi propia autoría, porque creo que esa técnica pictórica es ligera, no como el óleo. Y yo misma las pinto y después les doy movimiento, con mi equipo de animadores. Porque yo soy una convencida de la obra de arte total, instancia en la que intento plasmar mi visión de mundo, y la acuarela es transparente, me permite eso, pues me da la ligereza que deseo plasmar y me sugiere la inocencia, lo lúdico del cuento infantil (cit. en Morales Lastra 2014).

Para Morales Lastra (2014) el montaje conceptual por el que optó Singer, sin una concepción de espacio-tiempo determinada, más una escena de coloridos vestuarios y "una propuesta escenográfica principalmente inspirada en lo audiovisual", fue acorde a "una trama cargada de símbolos, la que tiene, como trasfondo, la lucha soterrada entre el bien y el mal, un tema profundamente humano" (Morales Lastra 2014).

Volviendo al Teatro Municipal de Las Condes, la siguiente obra fue Gianni Schicchi de G. Puccini, ópera bufa en cartelera a partir de agosto de 2015, con seis funciones y dos elencos. Browne dirigió una orquesta de veinticinco músicos y Singer se ocupó de la régie, escenografía, vestuario e iluminación. Está inspirada en parte del "Infierno" de la Divina Comedia de Dante y deja al descubierto la intriga, intereses, venganza, envidia y otras debilidades o defectos al interior de la familia. Según Singer, optó por ambientarla en el siglo XXI ya que "a pesar de los años, la arquitectura moral de los personajes sigue siendo la misma: en todos los siglos hemos sido testigos de la misma situación: familias que se pelean dramáticamente por una herencia" (Lennon 2015). Su énfasis estuvo en la farsa y no en la comedia y utilizó recursos de "la commedia dell' arte, el Tanztheater [danza teatro] de la bailarina y coreógrafa alemana Pina Bauch", así sus guiños apuntaban "especialmente a la expresividad del cuerpo humano" (Lennon 2015). En cuanto a la recepción del público, según Córdova (2015), este se entretuvo, aun cuando más de un conocedor de la obra pudo notar que el humor se sobrepasó, "desfigurando y caricaturizando demasiado al mayor contingente de personajes, pese a que algunos resultaron certeros, otros no lo fueron” (Córdova 2015).

En junio de 2016 Le convenienze ed inconvenienze teatrale de Donizetti fue el cuarto título programado en el teatro principal de la comuna de Las Condes, con seis funciones en junio de 2016. Esta ópera ya se había presentado en 2012 en el Centro de Extensión UC con distinto elenco, como se comentó antes.

En 2018 la penúltima ópera en escena en el Teatro Municipal de Las Condes fue un ícono del género lírico: La Traviata de Verdi. Tuvo diez funciones entre el 9 y 19 de agosto de 2018 y dos elencos alternados. Singer se encargó de la régie, diseño de escenografía, vestuario e iluminación y Eduardo Browne dirigió la orquesta. Sobre esta producción, Benner (2018) consideró "exitoso" el montaje en general. Felicitó la iniciativa de optar por cantantes nacionales mayormente jóvenes, la concepción de época, de gran gusto y respeto: "la estética imperante en los grandes salones a mediados del siglo decimonónico", y el vestuario, "rico en texturas y diseños", aunque acotó que quizás hubiese sido de más 
impacto visual un abanico tonal más amplio. La planta de movimiento para los cantantes le pareció "fluida y de atractiva dinámica, especialmente para aquellos de diseño asimétrico (Benner 2018)". En virtud de lo anterior y otras apreciaciones, concluyó que la propuesta fue "muy honesta, profesional y destacable desde todo punto de vista", considerando, además, que la orquesta fue expresiva y con bello sonido (Benner 2018). Se calcula que, en total, asistieron cerca de 7000 personas (Lennon 2019).

La sexta y última ópera ofrecida por el Teatro Municipal de Las Condes del binomio Singer-Browne fue Carmen (2019) de Georges Bizet. Con once funciones, entre el 14 y 24 de agosto 2019 y dos elencos alternados de cantantes, volvió a incorporar niños. Esta vez fue el Coro de Niños del Colegio Leonardo da Vinci de Las Condes, que se unió a actores y actrices, al igual que en La flauta mágica de 2006. Como siempre, Singer se hizo cargo de la dirección de escena, diseño de escenografía, vestuario e iluminación y Browne de la dirección de la orquesta, conformada por una treintena de músicos. Un reportaje de Maureen Lennon Zaninovic (2019) aportó algunas claves de las decisiones de Miryam Singer: "La puesta en escena se sitúa entre una visión clásica y ciertas estrategias de innovación. Manteniendo los ingredientes y los actores de la partitura, incluí algunas sorpresas, entre otras, elementos audiovisuales". También Singer declaró que es "una megaproducción", por el gran despliegue en escena, que además incluye "al gran bailaor Pedro Fernández y a su compañía de flamenco (Lennon 2019)".

Un tema no menor, del que ninguno de los críticos antes mencionados hizo referencia, es el contenido de los programas de mano que se entregan al público escritos por Singer, que complementan lo que el espectador ve en el escenario y que revelan claramente la intención de lo que desea comunicar en su producciones. Aunque pocos de su autoría están disponibles actualmente, estos, junto con el análisis de entrevistas concedidas a los medios escritos y los registros visuales de óperas de libre acceso en internet, permiten constatar que sus puestas en escena no son inocentes o ingenuas, si se prefiere: "El escenario de la ópera puedes convertirlo en un espacio simbólico, así, con el chasquido de los dedos y no tienes que anclarlo en una realidad conocida por fuerza. El problema de la mímesis en el teatro moderno no es la cuestión de la mímesis griega”, me comentó a propósito de su concepción de ópera (Peña 2021). En efecto, tras sus decisiones hay ideas, conceptos, una visión de mundo que subyace a la ficción y que transmite por medio de diferentes recursos. Son representaciones construidas en varias capas, no siempre lineales, produciéndose una estructura polifónica. A veces lo hace por medio del vestuario, en otras con la escenografía o los recursos de iluminación, audiovisuales, o bien con todos ellos. Así la temporalidad, la espacialidad o los énfasis de la historia son dinámicos; lo que sí está presente invariablemente en sus proyectos es su percepción de la ópera en conexión con el pasado y el presente o con el mundo real del dolor o la felicidad, de la pasión arrebatada o la tranquilidad taciturna, de la honestidad o la desvergüenza, en fin, con todos aquellos sentimientos y emociones -muchos duales- que experimenta el ser humano. Desde mi perspectiva esos y otros mensajes, a veces de problemáticas muy actuales, son un continuum en su visión ética de la ópera, reforzada por medio de los programas de mano. El texto que recibió el público de La Traviata en el Teatro Municipal de Las Condes ilustra someramente lo anterior.

Como es habitual en este tipo escritos, Miryam Singer (2018) primero sintéticamente contextualizó la obra en el marco de su tiempo, estableció vínculos entre la historia y el imaginario del compositor, además de caracterizar a sus principales personajes. Sin embargo, aprovechó el drama de esta mujer libertaria -Violeta- para incluir una reflexión amplia en torno a la situación de la mujer, históricamente desplazada, relacionándola con la vida de Violeta. De este modo, acerca del trasfondo de la historia, Singer comentó: "Es una historia preñada de asimetrías fundadas en la asignación de roles, en el ejercicio del poder, en la subdivisión del espacio público y privado", heredadas atávicamente por generaciones. Una 
vida de renuncia "a la búsqueda de su propio destino para supeditarlo al de su contraparte". Más categórica fue al escribir: "La Traviata fue niña abusada, abandonada y debió usar sus habilidades comparativas para proveerse el sustento. En su sistema de valores el ideal de la familia burguesa no tuvo tiempo ni oportunidad de entrar y pronto ella se acostumbró a vivir a la vera del camino (Singer 2018)”. Por último, casi al finalizar agregó:

Ahora que entró en nuestro lenguaje cotidiano el concepto de pedofilia, de abuso sexual, de falta de oportunidad, de ingresos segregados por género, podemos entender y establecer los paralelos entre esta historia de ficción y la pequeña historia de millones de personas, hombres y mujeres, que suscriben durante siglos a este orden inicuo y sufrieron por igual sus consecuencias (Singer 2018).

Aunque por limitaciones de espacio no es posible analizar otros programas de mano ni profundizar en este tema, para finalizar, es importante decir que este no fue el único caso en el que, a partir de la historia, trató problemáticas relacionadas con las mujeres, el poder o el juicio social, entre otras. Su actualización de la mirada de las historias, en mi opinión, es parte de una postura ética que ha mantenido en el tiempo.

El estallido social de fin de 2019 y luego la pandemia del COVID-19, con el confinamiento que a todos afectó en 2020 y 2021, dejaron en compás de espera nuevas producciones presenciales de Miryam Singer. Sin embargo, como Directora de Artes y Cultura de la Vicerrectoría de Investigación de la Pontificia Universidad Católica de Chile, siguió promoviendo la ópera desde las plataformas digitales. Por ejemplo, en el marco del programa "Artifica la UC4" o "Artifica tu casa (en época de pandemia)", creado y consolidado bajo su dirección, Singer ofreció en 2020 la charla "Las mujeres de Mozart" y "La ópera para niños o niños en la ópera ¿por qué tan infrecuente?" en 2021, de libre acceso en la plataforma YouTube. La audiencia que alcanzó la versión completa 2020 y 2021 fue de más de 20000 espectadores $^{5}$.

\section{PALABRAS FINALES}

Miryam Singer fue moldeando su ruta de viaje paso a paso y sin mayores alardes, pese a que, desde hace tiempo, año a año sorprende y pasa al centro de la noticia artística por una o más producciones de ópera. De pronto, y como si los astros se hubiesen alineado, en 2020 recibió tres importantes reconocimientos: la titularidad académica en la Pontificia Universidad Católica de Chile, la Academia Chilena de Bellas Artes del Instituto de Chile la invitó a incorporarse como Académica de Número, ocupando el sillón que antes fuera de la cantante y compositora Sylvia Soublette (1923-2020), y recibió el Premio Nacional de Artes Musicales, "por su extraordinaria trayectoria nacional e internacional", como dice el acta del jurado.

El perfil de su trayectoria aquí trazado, por cierto fragmentario, no hace más que presentar y visibilizar una parte de ese camino recorrido -quizás el más visible-y el significativo aporte que ha realizado en pro de la música y, en particular, de la ópera en nuestro país como cantante y directora, tanto desde la academia como de la gestión personal. Muchos temas de relevancia quedaron pendientes. Por ejemplo, su experiencia internacional, su labor como maestra, la proyección de su oficio a nuevas generaciones, o bien, su perspectiva

4 Artifica la UC tiene por objetivo promover la creación de obras artísticas producidas por todos los integrantes de la Comunidad UC por medio de proyectos.

5 Agradezco la gentileza de Javiera Sandoval, Coordinadora de Artes y Cultura, por proporcionarme este y otros datos importantes para este trabajo. 
y reflexión acerca del proceso creativo, que le han permitido siempre ir un paso más allá de la producción anterior. ¿Cómo se logra?, ¿se puede traspasar o enseñar?, ¿qué caminos podrían ser los más apropiados para que sea efectivo? Profundizar en ellos no solo permitiría matizar lo expuesto en las páginas anteriores, sino también completar de modo justo el perfil de una artista multifacética y comprometida con la cultura. Esto significa que no todo se ha dicho y es esperable que futuros trabajos puedan aportar en alguno o varios de los aspectos mencionados.

\section{BIBLIOGRAFÍA}

BenNer, Charles

2018 "La Traviata, artistas chilenos al palco escénico", Punto de Encuentro, 15 de agosto. www.chbcomentarios.blogspot.com Disponible en: https://8ead34d9-c0e2-4d99-ab36-552704649b6c. filesusr.com/ugd/6b6afa_039582ce58f64fe5b1b98fd6b579d727.pdf

Briceño, Víctor.

1994 "Aciertos y desaciertos", La Segunda, 12 de septiembre. Disponible en: https:/ /8ead34d9-c0e24d99-ab36-552704649b6c.filesusr.com/ugd/6b6afa_d435cb83b5364453afd08d9622966432. pdf [acceso: 30 de junio de 2021]

B. V.

1994 "Buena impresión de La Traviata nacional", El Mercurio, 13 de octubre. Disponible en: https://8ead34d9-c0e2-4d99-ab36-552704649b6c.filesusr.com/ugd/6b6afa_d435cb83b5364453afd08d9622966432.pdf [acceso: 30 de junio de 2021]

CARDONA

1991 "Cosí fan tutte", El Mercurio, 29 de mayo. Disponible en: https://8ead34d9-c0e2-4d99-ab36552704649b6c.filesusr.com/ugd/6b6afa_b784c55d7db44863807ca4b77ec47f92.pdf [acceso: 3 de abril de 2021]

Centro DAE

1992 "El Turco en Italia", Gioacchino Rossini, Opera Internacional. Disponible en: https://www. centrodae.cl/wp_cdae/?cat=18\&bs=miryam+singer\&x=9\&y=15\#resultados [acceso: $25 \mathrm{de}$ abril de 2021]

1993 "Carmen", Georges Bizet. Disponible en: https://www.centrodae.cl/wp_cdae/?cat=18\&bs $=$ miryam + singer $\& \mathrm{x}=10 \& \mathrm{y}=10 \#$ resultados [acceso: 25 de abril de 2021]

1996a “El Elixir de Amor", Gaetano Donizetti”. Disponible en: https://www.centrodae.cl/wp_cd ae/?cat=18\&bs=miryam+singer\&x=10\&y=10\#resultados [acceso: 10 de julio de 2021]

1996b "Elektra", Richard Strauss, Opera - Internacional". Disponible en: https://www.centrodae. cl/wp_cdae/?cat=18\&bs=miryam+singer\&x=9\&y=15\#resultados [acceso: 10 de julio de 2021]

Círculos de Críticos de Arte de Valparaíso.

1997 "Diploma la puesta en escena y dirección musical de Madama Butterfly". Disponible en: https://8ead34d9-c0e2-4d99-ab36-552704649b6c.filesusr.com/ugd/6b6afa_84ccd1973b19 43bd87blfb911919ce12.pdf [acceso: 10 de julio de 2021]

Comunicaciones de la Facultad de Artes.

2009 "Facultad de Artes se hace presente en Primer Festival de Ópera de Cámara" (5 de enero). Disponible en: https://www.uchile.cl/noticias/49300/fac-de-artes-se-hace-presente-enprimer-festival-de-opera-de-camara [acceso: 6 de octubre de 2021]

Corbella, Juana

2003 "Bitácora de Actividades IMUC. Septiembre 2002 / abril 2003", Resonancias VII/12 (mayo), pp. 95-113. [acceso: 12 de agosto de 2021] 
2006a "Bitácora de Actividades IMUC. Septiembre 2005 / Abril 2006", Resonancias X/18 (mayo), pp. 89-116. [acceso: 12 de agosto de 2021]

2006b "Bitácora de Actividades IMUC. Mayo / agosto 2006", Resonancias X/19, (noviembre), pp. 83-97. [acceso: 18 de agosto de 2021]

2007 "Bitácora de Actividades IMUC. Bitácora de Actividades IMUC. Septiembre 2006 / abril 2007”, Resonancias XI/20 (mayo), pp. 67-84. [acceso: 8 de septiembre de 2021]

Córdova, Mario

1991 "Cosí fan tutte": Una ópera blanca y radiante", La Época, 1 de junio. Disponible en: https:/ /8ead34d9-c0e2-4d99-ab36-552704649b6c.filesusr.com/ugd/6b6afa_b784c55d7db44863807ca4b77ec47f92.pdf [acceso: 3 de abril de 2021]

1993 "Los Puritanos" ( $2^{\circ}$ Elenco), La Época, 25 de agosto. Disponible en: https:/ /8ead34d9-c0e24d99-ab36-552704649b6c.filesusr.com/ugd/6b6afa_dd5641bb27b8405c8c3b14160dd86bae. pdf [acceso: 10 de junio de 2021]

1994a "La Sonámbula (segundo elenco)", El Mercurio, 23 de septiembre. Disponible en: https:/ /8ead34d9-c0e2-4d99-ab36-552704649b6c.filesusr.com/ugd/6b6afa_d435cb83b5364453afd08d9622966432.pdf [acceso: 30 de junio de 2021]

1994b "La Traviata en segundo elenco: triunfo total", La Época, 12 de octubre. Disponible en: https:/ /8ead34d9-c0e2-4d99-ab36-552704649b6c.filesusr.com/ugd/6b6afa_d435cb83b5364453afd08d9622966432.pdf [acceso: 30 de junio de 2021]

1995 “Ópera al mediodía”, El Mercurio, 5 de septiembre. Disponible en: https:/ /8ead34d9-c0e24d99-ab36-552704649b6c.filesusr.com/ugd/6b6afa_630ff03d88db48808afb8bcde686ace8. pdf [acceso: 30 de junio de 2021]

1997 "El ocaso de los dioses", La Época, 27 de mayo. Disponible en: https:/ /8ead34d9-c0e2-4d99ab36-552704649b6c.filesusr.com/ugd/6b6afa_24266702b13144bbabd90e157a474ff4.pdf [acceso: 30 de julio de 2021]

2009 "Un histórico "Orfeo", Las Últimas Noticias, 1 de febrero. Disponible en: https://8ead34d9c0e2-4d99-ab36-552704649b6c.filesusr.com/ugd/6b6afa_9f414d35eae741fca276a737e18c5 0ac.pdf [acceso: 20 de octubre de 2021]

2010 "Ingenioso "Don Pasquale" en la UC", Las Últimas Noticias, 20 de octubre. Disponible en: https:/ /8ead34d9-c0e2-4d99-ab36-552704649b6c.filesusr.com/ugd/6b6afa_53dfbb9f4b18 427b8d1451be94201159.pdf [acceso: 20 de octubre de 2021]

2012 "Donizetti, a pura farsa y cahuín”, Las Últimas Noticias, 20 de agosto. Disponible en: https:// www.miryamsinger.com/_files/ugd/6b6afa_0481833f581e47ac93dbbf9b262640df.pdf [acceso: 20 de octubre de 2021]

2013 "Mozart recibe a "Factor X", Las Últimas Noticias, 4 de septiembre. Disponible en: https:/ /8ead34d9-c0e2-4d99-ab36-552704649b6c.filesusr.com/ugd/6b6afa_c4c09a0a5e41420f9e1d69e3804c3508.pdf [acceso: 20 de octubre de 2021]

2015 "La farsa y la astucia se impusieron en 'Gianni Schicchi'”, Las Últimas Noticias, 31 de agosto. Disponible en: https://www.miryamsinger.com/_files/ugd/6b6afa_01057867abe14ac3b68 2a811978bd458.pdf [acceso: 22 de octubre de 2021]

De La SotTa, Romina

2021 "Miryam Singer: la urgencia de óperas para (y con) niños", Radio Beethoven, 20 de agosto. Disponible en: https://www.beethovenfm.cl/recomendado/miryam-singer-la-urgencia-deoperas-para-y-con-ninos/ [acceso: 8 de septiembre de 2021]

De La Sotta, Romina y Andrés Gómez

2020 "Miryam Singer, Premio Nacional de Artes Musicales 2020: "Este premio es un reconocimiento a la mujer e implica dar una vuelta de página”, La Tercera, 8 
de septiembre. Disponible en: https://www.latercera.com/culto/2020/09/08/ miryam-singer-premio-nacional-de-artes-musicales-2020-este-premio-es-un-reconocimientoa-la-mujer-e-implica-dar-una-vuelta-de-pagina/ [acceso: 8 de septiembre de 2021]

EDitorial, C.

1998 “Compositores en el país”, Revista Musical Chilena, LII/189, pp. 80-89. Disponible en: https:// revistamusicalchilena.uchile.cl/index.php/RMCH/article/view/13987/14287 [acceso: 30 de julio de 2021]

Escobar, SERgio

1997 "La Novena Sinfonía”, El Mercurio, 24 de julio. Disponible en: https:/ /8ead34d9-c0e2-4d99ab36-552704649b6c.filesusr.com/ugd/6b6afa_24266702b13144bbabd90e157a474ff4.pdf [acceso: 10 de julio de 2021]

Gutiérrez, Francisco

2002 “La Flauta Mágica' de Mozart: un montaje de extraordinaria calidad”, El Mercurio, 30 de julio. Disponible en: https:/ / 8ead34d9-c0e2-4d99-ab36-552704649b6c.filesusr.com/ugd/6 b6afa_331cd09ab40c480585cc5319c999624f.pdf [acceso: 10 de julio de 2021]

2005 "Una Tosca intensa y dramática", El Mercurio, 4 de abril. Disponible en: https:/ /8ead34d9-c0e24d99-ab36-552704649b6c.filesusr.com/ugd/6b6afa_fece01fcd8264caca6440ddc4ead823e. pdf [acceso: 26 de agosto de 2021]

Heinlein, FEDERICO

$1985 a$ "Programa Mozart", El Mercurio, 19 de abril. Disponible en: https://8ead34d9-c0e2-4d99ab36-552704649b6c.filesusr.com/ugd/6b6afa_6fb093e362214209a6eed7993814a8f0.pdf [acceso: 20 de marzo de 2021]

1985b "Dos conciertos", El Mercurio, 23 de noviembre. Disponible en: https:/ /8ead34d9-c0e2-4d99ab36-552704649b6c.filesusr.com/ugd/6b6afa_6fb093e362214209a6eed7993814a8f0.pdf [acceso: 20 de marzo de 2021]

1989a "Despedida de Volker Wangenheim”, El Mercurio, 23 de julio. Disponible en: https:/ /8ead34d9c0e2-4d99-ab36-552704649b6c.filesusr.com/ugd/6b6afa_9e91119558a54828a18268780136 2e02.pdf [acceso: 20 de marzo de 2021]

1989b "Páginas Estadounidenses", El Mercurio, 2 de octubre. Disponible en: https://8ead34d9c0e2-4d99-ab36-552704649b6c.filesusr.com/ugd/6b6afa_9e91119558a54828a1826878013 62e02.pdf [acceso: 20 de marzo de 2021]

1989c "Berg y Stravinski”, El Mercurio, 3 de diciembre Disponible en: https:/ /8ead34d9-c0e2-4d99ab36-552704649b6c.filesusr.com/ugd/6b6afa_9e91119558a54828a182687801362e02.pdf [acceso: 3 de abril de 2021]

1990a “Temporada Filarmónica”, El Mercurio, 10 de marzo. Disponible en: https:/ /8ead34d9-c0e24d99-ab36-552704649b6c.filesusr.com/ugd/6b6afa_3893ea672ae647108a6d6c43b560ccfd. pdf [acceso: 3 de abril de 2021]

1990b "Entendimiento armonioso", El Mercurio, 26 de agosto. Disponible en: https://8ead34d9c0e2-4d99-ab36-552704649b6c.filesusr.com/ugd/6b6afa_3893ea672ae647108a6d6c43b560 ccfd.pdf [acceso: 3 de abril de 2021]

1992a "Veltri en Beethoven", El Mercurio, 25 de febrero. Disponible en: https://8ead34d9-c0e24d99-ab36-552704649b6c.filesusr.com/ugd/6b6afa_5723f78c16c4486682a67ea9fbc1cebe. pdf [acceso: 25 de abril de 2021]

1992b “Cuarto programa de la Sinfónica”, La Época, 15 de junio. Disponible en: https:/ /8ead34d9c0e2-4d99-ab36-552704649b6c.filesusr.com/ugd/6b6afa_5723f78c16c4486682a67ea9fbc1c ebe.pdf [acceso: 25 de abril de 2021]

1992c "Misa en Si menor, de Bach”, El Mercurio, 15 de diciembre. Disponible en: https://8ead34d9c0e2-4d99-ab36-552704649b6c.filesusr.com/ugd/6b6afa_5723f78c16c4486682a67ea9fbc1c ebe.pdf [acceso: 25 de abril de 2021] 
1992d "Stabat Mater, Dvorak”, El Mercurio, 19 de diciembre. Disponible en: https://8ead34d9c0e2-4d99-ab36-552704649b6c.filesusr.com/ugd/6b6afa_5723f78c16c4486682a67ea9fbc1 cebe.pdf [acceso: 25 de abril de 2021]

1993a "Izquierdo en el Teatro Oriente", El Mercurio, 10 de julio. Disponible en: https:/ /8ead34d9-c0e24d99-ab36-552704649b6c.filesusr.com/ugd/6b6afa_dd5641bb27b8405c8c3b14160dd86bae. pdf [acceso: 10 de junio de 2021]

1993b “Cámara en Las Condes", El Mercurio, 31 de julio. Disponible en: https://8ead34d9-c0e24d99-ab36-552704649b6c.filesusr.com/ugd/6b6afa_dd5641bb27b8405c8c3b14160dd86bae. pdf [acceso: 10 de junio de 2021]

1993c "Clausura de Temporada", El Mercurio, 20 de octubre. Disponible en: https://8ead34d9-c0e24d99-ab36-552704649b6c.filesusr.com/ugd/6b6afa_dd5641bb27b8405c8c3b14160dd86bae. pdf [acceso: 10 de junio de 2021]

1993d “Un Réquiem Alemán”, El Mercurio, 20 de diciembre. Disponible en: https:/ /8ead34d9-c0e24d99-ab36-552704649b6c.filesusr.com/ugd/6b6afa_dd5641bb27b8405c8c3b14160dd86bae. pdf [acceso: 10 de junio de 2021]

1998 "Requiem, de G. Verdi”, El Mercurio, 24 de mayo. Disponible en: https://8ead34d9-c0e24d99-ab36-552704649b6c.filesusr.com/ugd/6b6afa_6b3d69fe57f642e0aea5ee9714c1c8e3. pdf [acceso: 30 de junio de 2021]

Lennon Zaninovic, Maureen

2012 "El pequeño Municipal”, El Mercurio, 13 de mayo. Disponible en: https:/ /www.miryamsinger. com/_files/ugd/6b6afa_6334ba15346a4540ae683ecbddf8e3ec.pdf [acceso: 20 de octubre de 2021].

[2012] "El Pequeño Municipal se atreve con obra de Falla”, El Mercurio, [noviembre] En https://www. miryamsinger.com/_files/ugd/6b6afa_4ffc2fa609ed42508ee4649b8d55bcbf.pdf [acceso: 20 de octubre de 2021].

2013 "Teatro Municipal de La Condes incursiona en la ópera”, El Mercurio, 3 de agosto. Disponible en: https:/ /8ead34d9-c0e2-4d99-ab36-552704649b6c.filesusr.com/ugd/6b6afa_f0a91b82ac9c4adeb511772028c35d21.pdf [acceso: 20 de octubre de 2021]

S/F “Así es la 'Madama Butterfly' que llegará a Las Condes”. [El Mercurio]. Disponible en: https:/ /8ead34d9-c0e2-4d99-ab36-552704649b6c.filesusr.com/ugd/6b6afa_127dbf8acf49 401fa5e92f2de130de42.pdf [acceso: 22 de octubre de 2021]

2014 "Verónica y Maribel Villarroel protagonizarán 'Madama Butterfly", El Mercurio, viernes 2 de mayo. Disponible en: https://8ead34d9-c0e2-4d99-ab36-552704649b6c.filesusr.com/ug d/6b6afa_127dbf8acf49401fa5e92f2de130de42.pdf [acceso: 22 de octubre de 2021]

2015 "Miryam Singer y Eduardo Browne: esta es una pequeña pintura de la miseria humana”, El Mercurio, 16 de agosto. Disponible en: https://www.miryamsinger.com/_files/ugd/6b6afa _243f062b226e4fe791f236389880625f.pdf [acceso: 22 de octubre de 2021]

2019 "Teatro Municipal de Las Condes se deja seducir por 'Carmen’”, El Mercurio, 29 de julio. Disponible en: https://8ead34d9-c0e2-4d99-ab36-552704649b6c.filesusr.com/ugd/6b6afa_ f377bbf74d014c288ade966043838731.pdf [acceso: 22 de octubre de 2021]

LETELIER, JORGE

2009 "Opera El Rapto en el Serrallo se presenta hoy gratis en la Plaza de Armas", La Tercera online, 13 enero. Disponible en: https://www.latercera.com/noticia/opera-el-rapto-en-el-serrallose-presenta-hoy-gratis-en-la-plaza-de-armas / [acceso: 6 de octubre de 2021]

LÓPEZ, LEONORA

2007 "Bitácora de Actividades IMUC. Mayo / septiembre 2007”, Resonancias XI/21 (noviembre), pp. 89-98. [acceso: 12 de agosto de 2021] 
2008 "Bitácora de Actividades IMUC. Mayo / septiembre 2008", Resonancias XII/23 (noviembre), pp. 99-105. [acceso: 12 de agosto de 2021]

Matamoros, Ximena

2020 "Entrevista a Miryam Singer", Foro de las Artes 2020: "Resistencias", Universidad de Chile. Disponible en: https:/ / www.youtube.com/watch?v=NQrdjh1XQoQ [acceso: 11 de noviembre de 2021]

Meléndez, Pablo

1989 "Bernstein y Gershwin en el Baquedano", La Época, 2 de octubre. Disponible en: https://8ead34d9-c0e2-4d99-ab36-552704649b6c.filesusr.com/ugd/6b6afa_9e91119558a 54828a182687801362e02.pdf [acceso: 20 de marzo de 2021]

Metro de Santiago

2006 "Más de 4 mil personas disfrutaron ópera 'Bodas de Fígaro’ en Metro" (9 de junio). Disponible en https://www.metro.cl/noticias/detalle/52 [acceso: 13 de diciembre de 2021]

Morales Lastra, EnriQue

2014 "'La flauta mágica', el alegre montaje en el Municipal de la chilena Miryam Singer”, El Mostrador, 30 de octubre. Disponible en: https://www.elmostrador.cl/cultura/2014/10/30/ la-flauta-magica-el-alegre-montaje-en-el-municipal-de-la-chilena-miryam-singer/ [acceso: 22 de octubre de 2021]

Muñoz, Juan Antonio

2000 "Admirable 'Clemencia' nacional”, El Mercurio, 31 de julio. Disponible en: https:/ /8ead34d9-c0e2-4d99-ab36-552704649b6c.filesusr.com/ugd/6b6afa_d4b4959dc4cf4123b5046f3ad12b40a6.pdf [acceso: 18 de agosto de 2021]

2001 "Vigoroso Falstaff" (versión nacional), El Mercurio, 7 de noviembre. Disponible en: https:/ / 8ead34d9-c0e2-4d99-ab36-552704649b6c.filesusr.com/ugd/6b6afa_ed1fee6bad9f42f0867415c6f2060e40.pdf [acceso: 18 de agosto de 2021]

2002 "Clímax sonoro, error escénico (elenco nacional)", El Mercurio, 1 de julio. Disponible en: https:/ /8ead34d9-c0e2-4d99-ab36-552704649b6c.filesusr.com/ugd/6b6afa_331cd09ab40c 480585cc5319c999624f.pdf [acceso: 18 de agosto de 2021]

[2009] "Un Mozart popular, joven y vibrante". Disponible en: https://8ead34d9-c0e2-4d99-ab36552704649b6c.filesusr.com/ugd/6b6afa_9f414d35eae741fca276a737e18c50ac.pdf [acceso: 6 de octubre de 2021]

2009 "La Serva Patrona, Pergolesi: 'La nana' llega a la ópera”, El Mercurio, 28 de septiembre. Disponible en: https:/ /8ead34d9-c0e2-4d99-ab36-552704649b6c.filesusr.com/ugd/6b6afa _la0b1fa04c0041d8af649c7d51247330.pdf [acceso: 20 de octubre de 2021]

2011 "Der Kaiser Von Atlantis en la UC: Montaje estremecedor", El Mercurio 29 de septiembre. Disponible en: https:/ /8ead34d9-c0e2-4d99-ab36-552704649b6c.filesusr.com/ugd/6b6afa _9324d0357e884500af29c70fa7a2cc07.pdf [acceso: 20 de octubre de 2021]

MuÑoz, Víctor

1985 "Andrea Chenier", El Mercurio, 17 de septiembre. Disponible en: https://8ead34d9-c0e24d99-ab36-552704649b6c.filesusr.com/ugd/6b6afa_6fb093e362214209a6eed7993814a8f0. pdf [acceso: 20 de marzo de 2021]

1990 "Fausto", El Mercurio, 15 de octubre. Disponible en: https://8ead34d9-c0e2-4d99-ab36552704649b6c.filesusr.com/ugd/6b6afa_3893ea672ae647108a6d6c43b560ccfd.pdf [acceso: 3 de abril de 2021]

PAssalacQua, ÍtAlo

1989 "La orquesta Sinfónica ofrece atractivo programa musical contemporáneo", La Segunda, 5 de diciembre. Disponible en: https: / /8ead34d9-c0e2-4d99-ab36-552704649b6c.filesusr.com/ ugd/6b6afa_9e91119558a54828a182687801362e02.pdf [acceso: 20 de marzo de 2021] 
1991 “Glamorosa y vocalmente sólida emerge ópera 'Cosí fan tutte”, La Segunda, 28 de mayo. Disponible en: https:/ /8ead34d9-c0e2-4d99-ab36-552704649b6c.filesusr.com/ugd/6b6afa_ b784c55d7db44863807ca4b77ec47f92.pdf [acceso: 3 de abril de 2021]

1991b "Al más puro estilo de los efectos especiales es puesta en escena de 'La flauta mágica”, $L a$ Segunda, 13 de septiembre. Disponible en: https:/ /8ead34d9-c0e2-4d99-ab36-552704649b6c. filesusr.com/ugd/6b6afa_b784c55d7db44863807ca4b77ec47f92.pdf [acceso: 25 de abril de 2021]

Peña, Carmen

2019 "Federico Heinlein Funcke (1912-1999): mediador entre el público y la música", Anales del Instituto de Chile, vol. XXXVIII, pp. 131-148.

2021 Entrevista personal a Miryam Singer. Santiago, 28 de octubre.

Ponce, Gilberto

2009 "Ópera de Cámara. Función para 6.000 personas", Emol, 19 de enero. Disponible en: https://8ead34d9-c0e2-4d99-ab36-552704649b6c.filesusr.com/ugd/6b6afa_9f414d35eae7 41fca276a737e18c50ac.pdf [acceso: 6 de octubre de 2021]

2011 "Der Kaiser Von Atlantis, un viaje al centro del asombro". www.visionescriticas.cl, 5 de octubre. Disponible en: http://www.visionescriticas.cl/?p=2722 [acceso: 20 de octubre de 2021]

Pontificia Universidad Católica de Chile

2010 Cuenta Rectoría 2009. Publicaciones UC, Tomo 2, pp. 3, 51. https://rectoria.uc.cl/wp-content/ uploads/cuentas-rectoria/cuenta-de-rectoria-2009-tomoII.pdf [acceso: 20 de octubre de 2021]

Quiroga, DANIEL

1990 "Frutillar: voces finales", El Mercurio, 8 de febrero. Disponible en: https://8ead34d9-c0e24d99-ab36-552704649b6c.filesusr.com/ugd/6b6afa_3893ea672ae647108a6d6c43b560ccfd. pdf [acceso: 3 de abril de 2021]

1993 "Los Puritanos”, El Mercurio, 31 de agosto. Disponible en: https:/ /8ead34d9-c0e2-4d99-ab36552704649b6c.filesusr.com/ugd/6b6afa_dd5641bb27b8405c8c3b14160dd86bae.pdf[acceso: 10 de junio de 2021]

1995 “Cosí fan tutte”, La Época, 6 de eptiembre. Disponible en: https:/ /8ead34d9-c0e2-4d99-ab36552704649b6c.filesusr.com/ugd/6b6afa_630ff03d88db48808afb8bcde686ace8.pdf [acceso: 30 de junio de 2021]

1996 “Bailes de Máscaras II”, El Mercurio, 3 de septiembre. Disponible en: https:/ /8ead34d9-c0e24d99-ab36-552704649b6c.filesusr.com/ugd/6b6afa_a3e86ec22beb4a879c6be50b24111818. pdf [acceso: 10 de julio de 2021]

1997 "El ahijado de la muerte (II)”, El Mercurio, 23 de octubre. Disponible en: https://8ead34d9c0e2-4d99-ab36-552704649b6c.filesusr.com/ugd/6b6afa_24266702b13144bbabd90e157a47 4ff4.pdf [acceso: 30 de julio de 2021]

1998a “La Traviata II”, El Mercurio, 1 de agosto. Disponible en: https:/ /8ead34d9-c0e2-4d99-ab36552704649b6c.filesusr.com/ugd/6b6afa_6b3d69fe57f642e0aea5ee9714c1c8e3.pdf[acceso: 30 de julio de 2021]

1998b "El Murciélago II", El Mercurio, 5 de septiembre. Disponible en: https://8ead34d9-c0e24d99-ab36-552704649b6c.filesusr.com/ugd/6b6afa_6b3d69fe57f642e0aea5ee9714c1c8e3. pdf [acceso: 12 de agosto de 2021]

2000 "De Bach a Gerschwin [sic]", El Mercurio, 2 de octubre. Disponible en: https:/ /8ead34d9-c0e24d99-ab36-552704649b6c.filesusr.com/ugd/6b6afa_d4b4959dc4cf4123b5046f3ad12b40a6. pdf [acceso: 12 de agosto de 2021]

2001 "La Misa de Réquiem, desafío verdiano", El Mercurio, 18 de julio. Disponible en: https:/ /8ead34d9-c0e2-4d99-ab36-552704649b6c.filesusr.com/ugd/6b6afa_ed1fee6bad9f42f0867415c6f2060e40.pdf [acceso: 12 de agosto de 2021] 
SiNGER, Miryam

2009 "La serva padrona. Programa de mano". Disponible en: https:/ /8ead34d9-c0e2-4d99-ab36552704649b6c.filesusr.com/ugd/6b6afa_af2dac3c832b419d8214d09054235b18.pdf [acceso: 20 de octubre de 2021]

2013 "Così fan tutte o la condicción humana". Programa de mano". Disponible en: https:/ /8ead34d9-c0e2-4d99-ab36-552704649b6c.filesusr.com/ugd/6b6afa_f0a91b82ac9c4adeb511772028c35d21.pdf [acceso: 22 de octubre de 2021]

2018 "Violeta Valéry, o el comienzo de un nuevo orden". Programa de mano de La Traviata, Teatro Municipal de las Condes. Disponible en: https:/ / 8ead34d9-c0e2-4d99-ab36-552704649b6c. filesusr.com/ugd/6b6afa_127dbf8acf49401fa5e92f2de130de42.pdf [acceso: 22 de octubre de 2021]

Spencer, Christian

2004 "La crítica musical en Chile: reflexiones sobre un oficio en transición", Resonancias 14 (mayo), pp. 5-11.

Subiabre, Malucha

2010 "Bitácora de Actividades IMUC septiembre 2009 / abril 2010", Resonancias XIV/26 (junio), pp. 77-84.

V. M.

1998 "La Traviata con Miryam Singer”, La Segunda, 30 de julio. Disponible en: https:/ /8ead34d9c0e2-4d99-ab36-552704649b6c.filesusr.com/ugd/6b6afa_6b3d69fe57f642e0aea5ee9714c1c 8e3.pdf [acceso: 30 de julio de 2021]

Wilckens, Sylvia

S/F "Una sobresaliente Carmen en el Teatro Municipal de las Condes". Disponible en: https:/ /8ead34d9-c0e2-4d99-ab36-552704649b6c.filesusr.com/ugd/6b6afa_c9655eba4e7341a4a32bdfa163dec8d0.pdf [acceso: 22 de octubre de 2021]

Audiovisuales

Singer, Miryam

2006 "Los niños de Chile cantan la Flauta Mágica”. Disponible en: https://www.youtube.com/ watch?v=x5uhjxCe-OI\&t=8s [acceso: 8 de septiembre de 2021]

2007 "Pierrot lunaire". Disponible en: https://www.youtube.com/watch?v=5BKYRSA7um0\&t=1s [acceso: 6 de octubre de 2021]

[2008] "Abriendo la cortina de... Festival de Cámara UC". Disponible en https://www.youtube. com/watch?v=NEkv8e4rLzA\&t=2s [acceso: 20 de octubre de 2021]

2009 El rapto en el Serrallo (reseña) Disponible en: https://www.youtube.com/watch?v=95zQSROlbM\&t=1s [acceso: 20 de octubre de 2021] 